Florida International University

FIU Digital Commons

FIU Electronic Theses and Dissertations

University Graduate School

3-18-2020

\title{
Self-Brand Connection Effects on Consumers Goal Pursuit Behavior
}

\author{
Ahmed Mohammed Alradadi \\ Florida International University, aalradad@fiu.edu
}

Follow this and additional works at: https://digitalcommons.fiu.edu/etd

Part of the Marketing Commons

\section{Recommended Citation}

Alradadi, Ahmed Mohammed, "Self-Brand Connection Effects on Consumers Goal Pursuit Behavior" (2020). FIU Electronic Theses and Dissertations. 4414.

https://digitalcommons.fiu.edu/etd/4414

This work is brought to you for free and open access by the University Graduate School at FIU Digital Commons. It has been accepted for inclusion in FIU Electronic Theses and Dissertations by an authorized administrator of FIU Digital Commons. For more information, please contact dcc@fiu.edu. 


\section{FLORIDA INTERNATIONAL UNIVERSITY}

Miami, Florida

\section{SELF-BRAND CONNECTION EFFECTS ON CONSUMERS GOAL PURSUIT BEHAVIOR}

A dissertation submitted in partial fulfillment of the

requirements for the degree of

DOCTOR OF PHILOSOPHY

in

BUSINESS ADMINISTRATION

by

Ahmed Mohammed Alradadi

2020 
To: Dean Joanne Li

College of Business

This dissertation, written by Ahmed Mohammed Alradadi, and entitled Self- Brand Connection Effects on Consumers Goal Pursuit Behavior, having been approved in respect to style and intellectual content, is referred to you for judgment.

We have read this dissertation and recommend that it be approved.

Jayati Sinha

William Humphrey

Leslie Frazier

Alexandra Aguirre Rodriguez, Major Professor

Date of Defense: March 18, 2020

The dissertation of Ahmed Mohammed Alradadi is approved.

Dean Joanne Li

College of Business

Andrés G. Gil

Vice President for Research and Economic Development and Dean of the University Graduate School

Florida International University, 2020 
(C) Copyright 2020 by Ahmed Mohammed Alradadi

All rights reserved. 


\section{ABSTRACT OF THE DISSERTATION}

\section{SELF-BRAND CONNECTION EFFECTS ON CONSUMERS GOAL PURSUIT BEHAVIOR}

by

Ahmed Mohammed Alradadi

Florida, International University, 2020

Miami, Florida

\section{Professor Alexandra Aguirre Rodriguez, Major Professor}

Marketers spend a considerable amount of their advertising dollars communicating the association between their brands and consumers' desired end states or goals. Although it is well established that consumers prefer brands that represent images and ideals they desire to achieve (Chen, Wan \& Levy, 2017), existing research is largely silent regarding when and how brands help versus hurt consumer goal pursuit. Thus, we need a greater understanding regarding when and how consumer use of brands to assist in goal pursuit is detrimental versus beneficial. Furthermore, the outcome of the consumer's brand-assisted goal pursuit is likely to affect their relationship with the brand, just as interpersonal goal pursuit affects personal relationships (Fitszimons and Fishbach, 2010).

In this dissertation, I argue that a self-brand connection determines whether brands would be effective in helping consumers achieve their goals or detrimental. Across four main studies, including fictional scenarios, engaging in a writing task, and solving anagrams, I found that selfbrand connection influences consumers perceived progress, subsequent choices, and other goalrelated constructs such as goal difficulty and goal commitment. Importantly, results from studies conducted in this research suggest that, indeed, self-brand connection influences consumer 
behavior during the goal pursuit, accordingly contributing to research interested in self-brand connection and goal research in general.

The work of this dissertation contributes to marketing theory by providing a better understanding of the self-brand connection and its psychological impact on consumers during the goal pursuit. In addition, the results reached in four different studies illuminate the importance of self-brand connection in terms of its positive and negative influence on different goal-related constructs such as perceived difficulty, progress, and goal-consistent choices.

Finally, this dissertation advances our current knowledge of the influence of self-brand connection on building strong relationships between consumers and brands by helping consumers to achieve their goals and provide the right feedback at the right time to enhance their chances of success. Self-serving attribution biases were included in the studies conducted in this dissertation, which will provide valuable information for marketing managers who are working with products that focus on goals such as Fitbit and Apple Watch.

Additionally, this dissertation expands our current knowledge regarding the self-brand connection construct itself. The definitional issues facing this construct are more likely to be resolved by studying the changes occurring to self-brand connection during different stages of the goal pursuit. 


\section{TABLE OF CONTENTS}

CHAPTER

I . INTRODUCTION

PAGE

II. LITERATTURE GAP

7

AP

III. D D S S E R TAT I O N ÖBJECTIVE

IV. RESEARCH FINDINIGS SUMMARY

V. CONCEPTUAL BACKGROUND

Basic Elements of Goal Pursuits

Goal Pursuit Stages

Action Initiation And Control Stage: Perceive Goal

Progress And Subsequent Choices

Goal Attainment/Failure Stage

Relationship of Goals to The Self-Concept

Brand Assisted GoalPursuit

VI. HYPOTHESE DEVELOPMENT

VIII. METHODS

Study 1 -

Study 2

Study 3

Study 4

VIII. Discussion 40

LIST OF REFERENCES

$\begin{array}{lr}\text { VITA } & 82\end{array}$ 


\section{Chapter 1: Introduction}

“Just do it-” Nike advertising campaign, 1988-current.

Renowned Harvard Business School Professor Theodore Levitt's famous quote "People don't want to buy a quarter-inch drill, they want a quarter-inch hole" underscores the fact that people use products to accomplish certain goals. Consumer goals range from highly concrete and utilitarian, such as making a quarter-inch hole, to highly abstract and value-expressive, such as being "the best." Consumers gravitate toward brands with images they associate with end states they desire to achieve. They associate brands with certain goals, in part, because of goal-related brand images portrayed through marketing communications, such as superior athletic performance with Nike athletic wear, feeling prosocial with Toms footwear, encouraging their creativity with Apple computer products, demonstrating thoughtfulness with Hallmark greeting cards, feeling beautiful and "worth it" with L'Oreal cosmetics, and loving the skin they are in with Olay skin products.

Extensive consumer research has shed light on the goal-driven processes that underlie consumer brand choice. For instance, consumers select brands that are congruent with their actual self-image or their ideal self-image depending on whether their goal is self-verification or self-enhancement, respectively (Escalas \& Bettman, 2003). As another example, research shows that consumers select compensatory brands when their self-acceptance is low, but choose adaptive brands when their self-acceptance is high (Kim \& Gal 2014). These studies demonstrate that consumers actively choose brands that they perceive will help them pursue certain goals. The gap that remains in the literature is the role of the brand in consumer goal pursuit. Do brands 
help or hurt consumers' striving toward their goals? I elaborate on this gap in the following section.

\section{Literature gap}

While many marketers spend a considerable amount of their advertising dollars communicating the association between their brands and consumers' goals, and although it is well established that consumers gravitate toward brands that represent images and ideals they desire to achieve (Chen, Wan \& Levy, 2017), existing research is largely silent regarding when and how brands help versus hurt consumer goal pursuit. Thus, we need a greater understanding regarding when and how consumer use of brands to assist in goal pursuit is detrimental versus beneficial. For example, Brick and Fitzsimons (2017) found that consumers who are low in relationship power (i.e. cannot face their frustration with their partner) chose brands that are less liked by their partner to "get even" with them instead of taking steps to solve the problem. The question remains as to whether the brand actually helped the consumers (e.g. made them feel better) or hurt them (e.g. reduced their motivation to solve the problem). Furthermore, the outcome of the consumer's brand-assisted goal pursuit is likely to affect their relationship with the brand, just as interpersonal goal pursuit affects personal relationships (Fitszimons and Fishbach, 2010).

The manner in which I fill this gap with this dissertation research is by bridging the brand relationship literature and goal pursuit literature to provide insights into when and how brands help or hurt consumer goal pursuit. The brand relationship research shows that consumers relate to brands in a manner similar as human relationships (Fournier, 1998). Research in the domain of psychology on "interpersonal goal pursuit" suggests that when individuals receive help from 
others (e.g., friends, family, co-workers) to achieve their personal goals, their relationship with the other person determines the individual's goal pursuit (Righetti, Kumashiro, \& Campbell 2014). Given that most consumer behavior is goal-driven and that branded products constitute a means to many of the ends consumer pursue, it stands to reason that in the same manner in which people's interpersonal relationships with friends and family who help them pursue a goal affects their goal striving and success, so must consumers' relationships with the brands that help them achieve their goals affect goal pursuit processes such as goal progress monitoring and making subsequent goal-(in)consistent choices.

This dissertation research focuses on a prevalent and influential type of consumer-brand relationship: self-brand connection (SBC), which refers to the psychological connection between a consumer and the brand, as well as the extent to which the consumer has incorporated the brand into their self-concept (Escalas \& Bettman, 2005). Consumers incorporate brands with desirable image associations into their self-concepts, and these can be related to consumers' personal goals. For example, the college athlete who strives to score in each game may choose Nike apparel, footwear, and gear to help him improve his athletic performance because he believes the brand helps him "Just do it." Thus, continuing with the prior example, the strength of the college athlete's self-brand connection with Nike will influence whether high versus low perceived progress toward his athletic performance improvement goal leads to goal-consistent or -inconsistent behavioral choices. Given that Individuals have limited resources in terms of time and energy, not every goal they pursue will be achieved. Thus, although the choice of a goalconsistent behavior after low goal progress represents persistence, the choice of a goalinconsistent behavior can be considered an adaptive response of disengaging from difficult goal (Brandstätter, 2003; Brandtstädter \& Rothermund, 2002; Wrosch, Scheier, Carver, \& Schulz, 
2003). While disengaging from goals is a commonplace occurrence, less is known about the process itself (Ghassemi, Bernecjer, Herrmann and Brandstatter, 2017). Thus, this dissertation sheds light on the manner in which SBC determines consumers' goal-(in)consistent choices following from low (vs. high) perceived goal progress. Furthermore, I propose that there is a feedback loop whereby perceived goal progress affects consumers' relationships with the goalassisting brand. Thus, in the example above about the college athlete, a feedback loop is likely to impact the college athlete's self-brand connection with Nike proceeding from high versus low perceived athletic performance improvement progress.

In related research, Cheng, White and Chaplin (2012) show that self-brand connection affects how consumers respond to brand failure as a function of their self-esteem goal (i.e., maintaining a positive self-evaluation). This research finds that when participants were presented with negative reviews (i.e., brand failure) about a high self-connection brand, they reported lower self-evaluation (e.g., self-esteem) than when they read negative reviews about a low selfconnection brand. However, these high (vs. low) self-brand connection participants' brand evaluations remained favorable despite the brand's failure. Cheng, et al (2012) explain this phenomenon as an ego-protection effect. In that high self-brand connection, consumers are reluctant to evaluate the brand negatively because they perceive their brand evaluation as reflective of their own self-evaluation. These results can also be explained in terms of the role of self-brand connection in brand-assisted goal pursuit that this dissertation postulates. More particularly, the high SBC brand failure can be construed as low progress toward the consumers' goal of maintaining positive self-esteem. Participants responded to this low goal progress by positively evaluating the brand; this contributed to boosting participants' self-esteem by minimizing the threat to their positive self-view. In other words, participants were motivated to 
make a self-esteem goal-consistent (positive) brand evaluation. Due to participants' high selfconnection to the brand, a negative evaluation would boomerang back toward the consumer's self-evaluation (Cheng, et al 2012), which is inconsistent with the goal of maintaining a positive self-view or self-esteem. Furthermore, although Cheng, et al (2012) did not specifically measure post-brand failure SBC, I surmise that high SBC participants' positive brand evaluation after brand failure suggests that the self-brand connection strength was maintained, which supports the feedback loop perspective I will present in this dissertation.

\section{Dissertation objective}

The objective of this dissertation is to propose and empirically test a theoretical model to explain how consumers' self-brand connections help or hinders consumers' goal pursuit efforts when they use brands to assist with goal setting and goal striving and how brand-assisted goal success/failure affects self-brand connections. To achieve this purpose, this research is driven by the following overarching questions. First, as it relates to how brands affect goal pursuit, how does self-brand connection strength affect perceived goal progress, and whether consumers choose goal-consistent or inconsistent subsequent behaviors? Second, how does goal failure affect the consumer's self-brand connection? More specifically, I argue that when consumers are using brands, they have high (low) self-connection with, they are more (less) likely to increases their perceived progress. Thus, when high (low) SBC brand assists with the goal pursuits, consumers are more (less) likely to make goal-inconsistent choices. Last, I predict that goal failure might affect consumers self-brand connection such that when consumers make low goal progress (i.e. fail) in brand-assisted goal pursuits, they are more likely to distance themselves from the brand thus decreasing their self-brand connection. 


\section{Research findings summary}

Four completed studies provide partial support for the theorized model by showing that self-brand connection strength does indeed affect perceived goal progress during the goal monitoring phase of goal pursuit, as well as goal-(in)consistent choice during the behavior adjustment phase. Furthermore, perceived goal progress also affects self-brand connection. Study 1 shows that self-brand connection has an effect on perceived progress and subsequent choices such that consumers who are using brands they have high self-brand connection are more likely to exaggerate their level of progress compared to those who are using low self-brand connection. In addition, consumers who are using high self-brand connection are more likely to make goalinconsistent choices compared to those who are using a low self-brand connection. In study 2 I used a manipulated self-brand connection instead of measure, and only the impact of the construct on subsequent choices was replicated in the same direction. Study 3 shows that the goal-outcome influences self-brand connection. As consumers fail in the goal pursuit, their level of connection to the brand weakened. On the other hand, when the goal-outcome is positive, consumers associate themselves with the brand, and their level of self-brand connection increases. Study 4 used a different goal pursuit (i.e., solving anagram), but due to problems with the main manipulation, the effects found in the previous three studies were not replicated.

\section{Dissertation organization}

This dissertation is organized as follows: First, the conceptual background section will elaborate on the two theoretical domains that the present research integrates to examine brandassisted goal pursuit: goal pursuit and consumer-brand relationships. Next, building on these two 
theoretical bases, I present the theoretical framework and hypotheses. Then four studies were conducted to test these hypotheses. Finally, I discuss the results of the studies.

\section{Chapter 2: Conceptual background}

The discussion of the conceptual background for this dissertation research focuses on two main areas. First, the domain of goal pursuit will be reviewed, focusing on two key sub-areas that are germane to this dissertation research: basic elements of goal pursuit (the nature of goals, motivation, and goal pursuit stages) and social influences on goal pursuit (reference group influences and interpersonal goal support)1. The latter leads to the logic for brand-supported goal pursuit, which is the focus of this dissertation. Following the discussion of goal pursuit research, I discuss the consumer-brand relationship literature, which contributes to understanding the brand's role when consumers include them in their goal pursuit efforts.

\section{Basic elements of goal pursuit}

\section{The nature of goals}

Goals are desirable end-states that are internally represented in people's minds (i.e., cognitive constructs) (Kruglanski, 1996) and toward which individuals direct their actions (Pervin 1989). Goal pursuit research elaborates on two broad attributes of goals that impact goal

${ }^{1}$ Although goal theory recognizes that successful goal attainment is partly determined by selfregulatory strategies, such as forming implementation intentions (Golwitzer \& Brandstatter, 1997), mentally simulating pathways toward goal completion (Taylor, Pham, Rivkin, \& Armor, 1998), and exerting willful self-control to resist temptations (Trope \& Fishbach, 2000), as well as possessing the cognitive resources to execute these goal-directed control efforts (Baumeister \& Vohs, 2007), the domain of self-regulatory processes is outside the scope of inquiry of this dissertation research. 
achievement: content and intensity (Latham \& Locke, 1991). Goal content varies in such features as desirability, feasibility, difficulty, specificity, importance, and abstractness. These characteristics are summarized in Table 1.

Although, in general, goals are desirable end-states, individuals are motivated to pursue goals that are higher in desirability than competing goals, meaning that the short- or long-term consequences of attaining the goal are deemed more attractive than those of competing goals. Goal importance determines how much effort individuals are willing to invest in their goal pursuit. Desirable goals might not be perceived as high in importance compared to other goals an individual is pursuing.

Expectancy-value theories of motivation (Heckhausen, 1977; Kuhl, 1982) suggest that individuals desire and commit to goals they perceive as more achievable, compared to goals they associate with a lower likelihood of success, which relates to the two independent characteristics of goal difficulty and feasibility. Goals may be deemed as difficult because of the amount of effort that is required to achieve the goal (Brehm \& Self, 1989; Wright \& Brehm, 1989). Dalton and Spiller (2012) found that having multiple goals might draw attention to the difficulty of the task, which affects commitment negatively. Bagozzi and Warshaw (1990) showed that goals' perceived difficulty could demotivate consumers from pursuing these goals. For example, when consumers perceive certain products to be expensive or limited, they will be demotivated even to try buying the products. Furthermore, goals typically entail some difficulty, as there is little reason to set easy goals (Hollenbeck and Klein, 1987).

Individuals sometimes seek the help of a significant other when pursuing goals. Research shows that a person's receptiveness to such interpersonal goal support varies with goal difficulty; individuals are less prone to seek a romantic partner's help for a difficult goal because it makes 
them feel less capable (Righetti, Kumashiro, \& Campbell, 2014). Individuals prefer to focus on their capability, which is referred to as self-efficacy beliefs. Goals seem feasible when the individual believes he or she is capable of performing goal-directed behaviors and that those behaviors will likely achieve the desired outcome (Bandura, 1997; Oettingen, 1996). Specificity is another influential characteristic of goals, which is "the degree of quantitative precision with which the aim [goal] is specified" (Lock, Shaw, Snarl \& Latham 1981, p. 126). For instance, the goal of saving $\$ 100$ reflects high specificity, whereas the goal of saving between $\$ 75-\$ 125$ reflects low specificity. Thus, goals that consumers pursue are not restricted to well defined endstates (e.g., visiting Hawaii in the summer) but also include open-ended and loosely defined endstates (e.g., taking an adventurous road trip) (Bagozzi \& Dholakia, 1999).

The second broad attribute of goals, goal intensity, is reflected in a person's commitment and effort toward achieving a goal (Latham \& Locke, 1991). Goal commitment essentially refers to whether a person chooses to engage in goal-consistent behaviors, expecting to achieve the goal eventually. Research shows that merely engaging in a goal-consistent behavior serves as a commitment cue, which motivates further goal-consistent behavior (Zhang \& Huang, 2010). This is important because individuals face the choice after performing a goal-consistent behavior of whether to continue pursuing the goal with another goal-consistent choice, or whether to disengage from goal pursuit by choosing a goal-inconsistent behavior. 
Table 1. Defining goal characteristics

\begin{tabular}{|c|c|}
\hline Characteristic & Definition \\
\hline Desirability & $\begin{array}{l}\text { The value of the goal to the individual. Why the individual chooses } \\
\text { to pursue the goal (Ghassemi, Bernecker, Herrmann, \& } \\
\text { Brandstatter, 2017). }\end{array}$ \\
\hline Feasibility & $\begin{array}{l}\text { Involves assessing the success likelihood of pursuing the goal } \\
\text { (Vann, Rosa, \& McCrea, 2018). }\end{array}$ \\
\hline Difficulty & $\begin{array}{l}\text { Assessment of the amount of effort, resources, capability required to } \\
\text { succeed in pursuing a goal (Sencko \& Harackiewicz, 2005). }\end{array}$ \\
\hline Specificity & $\begin{array}{l}\text { The extent to which the goal is quantified precisely (i.e., I want to } \\
\text { lose a lot of weight vs. I want to lose } 15 \text { pounds) (Lock, et al., } \\
\text { 1981). }\end{array}$ \\
\hline Importance & $\begin{array}{l}\text { Involves the relative decision weight the individual ascribes to the } \\
\text { goal at a given moment (Van Osselaer \& Janiszewski 2012). }\end{array}$ \\
\hline Abstractness & $\begin{array}{l}\text { Refers to the goal's level in the goal hierarchy, supra-ordinate, } \\
\text { focal, or subordinate. The most abstract level are superordinate } \\
\text { goals ("Why do I want to achieve that for which I strive?"), the next } \\
\text { level below the superordinate goal is more concrete, and referred to } \\
\text { as the focal goal ("What is it I am striving for?"), and the lowest } \\
\text { level, below the superordinate goal, is the most concrete ("How do I } \\
\text { achieve that for which I strive?") (Bagozzi \& Dholakia, 1999). }\end{array}$ \\
\hline Commitment & $\begin{array}{l}\text { Reflects a person's decision to pursue a goal because they expect to } \\
\text { eventually achieve the goal (Zhang \& Huang, 2010). }\end{array}$ \\
\hline
\end{tabular}


While goal pursuit can operate with or without conscious awareness, conscious goals cannot be triggered automatically by environmental cues (Chartrand and Bargh, 1996), and influence consumer behavior without deliberation or conscious influence. This dissertation focuses on conscious or deliberate goal pursuit wherein the individual is consciously aware of his or her goal, purposefully selects a brand to help with goal pursuit, and intentionally uses the brand during goal striving.

\section{Goal Pursuit Stages}

Consumers perform multiple complex mental activities during goal pursuit. Bagozzi and Dholakia (1999) proposed a framework of six stages of goal-directed consumer behavior that distinguishes between goal setting and goal striving stages (see Figure 1). According to this framework, the first step is goal setting, where consumers decide which goals they can pursue and why they should pursue them. Given sufficient motivation to pursue a desired goal, the goal pursuit process begins. This framework emphasizes volitional goal pursuit, in contrast to habitual, impulsive, or nonconscious goal pursuit, which is also the emphasis of this dissertation research. In this context, goal pursuit initiates with the formation of a goal intention (e.g., "I intend to lose 10 pounds," "I intend to raise my GPA," or "I intend to reduce my credit card debt"). Subsequently, the action planning stage involves thinking about where, when, how, and for how long they should pursue the goal. After that, consumers engage in action initiation and control, where they examine their progress, make any needed adjustments, and decide if the goal is still important to them. The fifth step is goal attainment or failure, where consumers assess whether they achieved or failed to accomplish the goal. The last step is feedback reactions, where individuals think about how they feel about their goal outcome and potentially revise their goal. 
Figure 1. Goal Setting and Goal Pursuit in Consumer Behavior (Bagozzi and Dholakia, 1999)

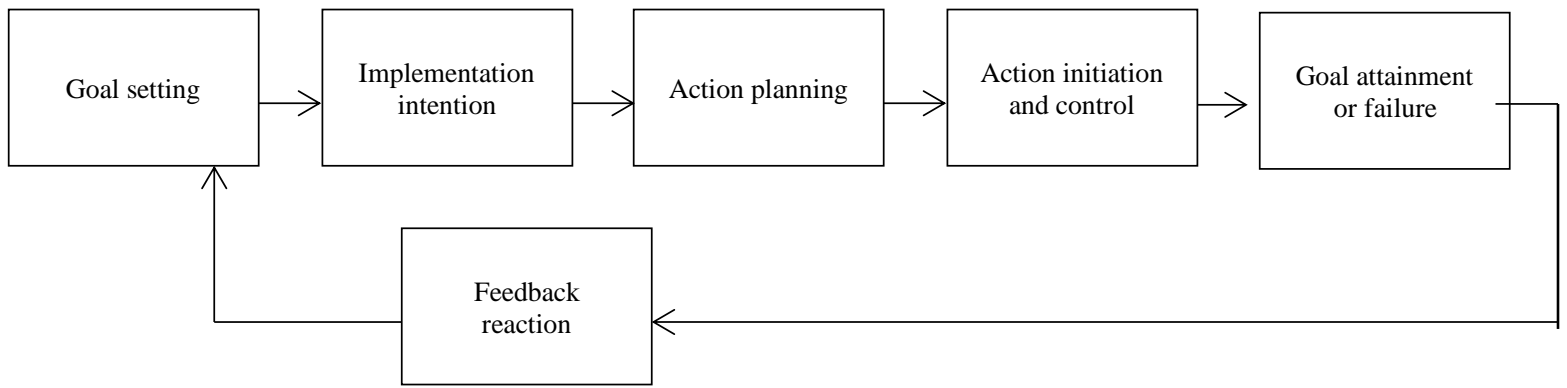

Given the purpose of this research to explain whether brands help or hinder goal pursuit, two stages are pertinent to this purpose: (1) action initiation and control, where individuals implement goal-directed actions and examine their progress and (2) goal attainment or failure, which involves a final comparison of the goal outcome to the standard set for the desired goal to determine whether to continue goal striving by maintaining or increasing current efforts or terminateing goal striving by disengaging from further efforts temporarily or permanently (Bagozzi \& Dholakia, 1999). Accordingly, the next section elaborates on research concerning these two goal pursuit stages.

\section{Action initiation and control stage: Monitoring goal progress}

Monitoring goal progress involves periodically examining a goal-directed behavior (e.g., how much one studied for a test) and/or its outcome (e.g., what grade one achieved on the test) and comparing these with standard that has been set (e.g., earn an "A") (Baumeister and Vohs, 2007; Carver and Scheier, 1982). Goal progress monitoring serves to help individuals identify discrepancies between their current state and desired state so that appropriate behavioral adjustment can be made to promote goal attainment (Harkin, Webb, Chang, Prestwich, Conner, Kellar, Benn, \& Sheeran, 2016). Such adjustment decisions constitute sequential choices, 
wherein an individual must follow up an initial goal action with the option of either a goalconsistent or goal-inconsistent action. Goal-inconsistent choices are accessible because individuals typically pursue several different behavioral goals at any given time that could contradict each other (e.g., studying to improve the GPA or hanging out with friends to have fun), and compete for the same resources such as time and energy. At times, people focus their efforts on maintaining a single goal (Bargh, Gollwitzer, Lee-Chai, Barndollar \& Trötschel 2001); thus, their subsequent choices are more likely to be goal-consistent. On the other hand, individuals could find themselves pursuing more than one goal at the same time. In such situations, individuals will try to "balance" their efforts between these goals, some of which could be contradictory to each other, and their subsequent choices could be either goal-consistent or goal-inconsistent (Dhar \& Simonsion 1999; Kivetz \& Simonson 2002). For example, when multiple goals were activated, consumers showed a degree of "balancing" in their subsequent choices, some of which were contradictory to the focal goal (Ariely \& Levav 2000; Drolet 2002; Ratner, Kahn, \& Kahneman 1999; Read \& Loewenstein 1995).

\section{Action initiation and control stage: Perceived goal progress and subsequent choices}

Progress refers to the perception that one is moving ahead on a goal by reducing the discrepancy between the current and desired end state (Carver \& Scheier, 1998). When individuals perceive that progress has been made toward the desired end state, a certain sense of partial goal attainment can ensue, which signals that goal striving efforts can be reduced since less effort is needed to accomplish the goal. Alternately, perceived failure to make adequate progress signals the need to increase goal striving efforts because more effort is needed (Carver 
\& Scheier, 1998; Higgins, 1987; Locke \& Latham, 1990; Miller, Galanter, \& Pribram, 1960; Powers, 1973).

Monitoring progress can increase motivation due to the goal gradient bias, wherein people tend to increase their goal striving efforts as they approach the end of goal pursuit (i.e., goal achievement) (Cryder, Loewenstein, \& Seltman, 2013; Kivetz, Urminsky, \& Zhang, 2006). Another study found that increased motivation and efforts in response to perceived goal progress are greater when progress seems fast (Koo \& Fishbach, 2012). Although research shows that monitoring goal progress can help goal striving, research also suggests that perceived progress can undermine goal pursuit because perceived progress produces positive feelings, which can result in reduced effort to maintain the current state of progress (Carver \& Scheier, 1998). Perceived progress can even encourage individuals to divert their efforts toward goalinconsistent behaviors (Amir \& Ariely, 2008; Fishbach and Dhar, 2005).

Fishbach, Zhang and Koo (2009)'s explanation for the mixed findings concerning perceived goal progress and subsequent goal-(in)consistent choices is that the decision to make subsequent goal-(in)consistent choices depends on the extent to which individuals view the initial goal-directed action as indicating goal progress versus goal commitment (for a review of determinants of commitment vs. progress representations of goal action see Fishbach, et al. 2009). Fishbach and colleagues proposed that when actions signal commitment, then individuals will highlight the focal goal, leading to goal-consistent choices. One the other hand, when actions signal progress, then individuals are more likely to balance their action and disengage from goals once satisfactory progress has been achieved. It logically follows, then, that if individuals start pursuing a goal in a commitment-induced representation, then, consistent with the goal gradient hypothesis, progress is more likely to motivate them to make more goal- 
consistent choices. In contrast, lack of progress would lead to perceiving their commitment as weak and likely to disengage from the goal. On the other hand, if individuals pursue a goal with a progress-representation, then when an initial goal action leads to inferring progress, the individual is more likely to subsequently disengage from the goal and follow another one (e.g., Fishbach and Dhar, 2005). But, when the initial goal action leads to inferring lack of progress, the individual is more likely to focus on the goal to make satisfactory progress before disengaging.

\section{Goal attainment/failure stage}

Whereas individuals periodically examine their goal progress and evaluate the extent of discrepancy between their current state and their desired state to regulate their goal striving efforts during the action control stage, the goal attainment/failure stage occurs at the end of goal striving and represents a final evaluation of the degree to which the goal was achieved or the degree of failure to achieve it. For example, if a person commits to a 12-week exercise program to lose 15 pounds, at the end of the 12 th week, the individual will compare their current state to the desired state of weight 15 pounds lower than their starting weight. The person's feelings about their success or failure at this stage can create a feedback loop that influences subsequent goal-setting. If the person feels positive about the goal attainment, then he may set a different health-related goal, such as lowering cholesterol, to pursue next. However, if the person feels negative about failing to meet the goal, he may decide to commit to another 12 -week exercise program, or try a different method, such as a nutrition-based program.

\section{Relationship of goals to the self-concept}

Goal pursuit has profound implications for the self-concept. Achieving valued goals 
increases an individual's image as competent and successful. People pursue goals to maintain aspects of their actual self, to achieve aspects of their ideal self, the type of person one desires to be, or ought self, the type of person one feels duty or obligation to be (Higgins, 1987), as well as to distance themselves from feared possible selves - the selves a person beliefs they might become in the distant future (Ruvolo \& Markus, 1986). Thus, the different facets of one's selfknowledge (e.g., actual self, ideal self, etc.) determine the cognitive component of one's superordinate goals (i.e., why consumers seek a specific goal out of many other competing goals) and subordinate (behavioral) goals (i.e., how individuals behave during goal pursuit) (Schlenker, 1985).

Self-deficits or self-discrepancies, the difference between how individuals want to be (i.e., the ideal-self) and how they view themselves to be (i.e., the actual self), creates a state of tension individuals seek to reduce (Higgins, 1987). Thus, self-deficits motivate individuals to take actions and move toward a desired end-state (i.e., goals) (Markus \& Wurf, 1987). Individuals become aware of self-deficits during goal progress monitoring by comparing their current state to their desired end state and evaluating the distance. Although individuals could reduce the psychological discomfort created by the self-discrepancy by readjusting their behavior and make choices that get them closer to the desired end-state (i.e., increase efforts toward goal striving), they could also engage in compensatory consumption, which is a type of behavior that helps individual avoid self-deficit information and protect their self-image (e.g., Gao, Wheeler, and Shiv 2009; Rucker and Galinsky, 2008). Compensatory consumption could help individuals avoid the negative information about the self by (1) symbolically "making up" for the aspect of the self 
that is related to the negative information (Gao et al. 2009) or by (2) avoiding paying attention to the information itself (Heatherton \& Baumeister, 1991).

\section{Brand-assisted goal pursuit}

Consumers use brands in various types of goal pursuits, such as social affiliation (Chen, Wan \& Levy, 2016), signaling status and wealth (Vigneron, Franck \& Johnson, 1999), selfenhancement (Escalas and Bettman, 2005), compensating for self-deficits (Kim \& Gal 2014), coping with loneliness (Long, Yoon \& Friedman, 2014) and coping with relationship conflict (Brick and Fitzsimons, 2017). Research elucidating the manner in which consumers relate to the brands that support their goal pursuit focuses on how consumers humanize brands from three perspectives (MacInnis and Folkes, 2017). First, the human-focused perspective discusses situations where consumers might perceive brands as having human-like features, such as personalities. Thus, a person may choose a brand with personality traits that are compatible with the situation, such as using a competent brand for a performance-related goal, but using a warm brand for a relational goal (Aaker, 1998; Fournier \& Alvarez, 2012). Second, the relationshipfocused perspective where studies focus on how consumers form relationships with brands that are governed by the same social rules that govern relations between people (Fournier 1998; Muniz Jr. \& O’Guinn, 2001, Blackston, 1993).

Consumers with the relationship-focused perspective may select brands to support their goal pursuit based on the nature of their relationship. A more important goal (e.g., getting pregnant to start a family) may encourage reliance on a brand that is a committed partner or best friendship. In contrast, for a less critical goal (e.g., decorating the nursery), the individual may enlist a brand that is a casual friend or a fling (Fournier, 1998). Third, and more intimately related to goal pursuits, the self-focused perspective which states that individuals view brands as 
oneself instead of a person by itself. For example, consumers might perceive the brand as being similar to themselves (i.e., brand-self congruity) (Sirgy, 1982). This perspective views the brand as a part of consumers' sense of self, "who they are, they have been, or they might become (MacInnis and Folkes, 2017). In this sense, the brand's role in supporting goal pursuit is that the brand's performance reflects the individual's goal striving performance. For example, the extent to which the cavity control toothpaste effectively minimized a person's dental cavity-formation, indicates whether the individual's goal of a favorable report at the next dental examination is achieved.

This type of self-focused brand humanization during goal pursuit can be detrimental for achieving goal success. Peloza, White \& Shang (2013) propose that humanized brands reduce consumers' accountability and sense of control during goal pursuit. Transfer of accountability toward the brand can lead consumers to engage in greater goal-inconsistent behavior. Thus, consumers are more likely to engage in goal-inconsistent behavior without actually noticing their need for self-control, a necessary condition for "readjusting behavior."

Clearly, there are conflicting views about brand-supported goal pursuit in the consumer brand choice literature. Although consumers have a relatively clear sense about the types of goals certain brands can help them pursue, there is the potential for the brand to get in the way of the consumer attaining their goal. Understanding when and how brands help versus hurt consumer goal pursuit is the purpose of the theoretical framework that I develop in the following section along with the research hypotheses. 


\section{Chapter 3: Hypotheses Development}

Prior research establishes that consumers choose brands that they believe will help them achieve certain goals. The issues that this dissertation addresses is whether pursuing a goal with the assistance of a brand that is strongly or weakly connected to the consumer's self-concept will help versus hinder goal pursuit. I approach this issue from the basis of the goal pursuit process and how the high (versus low) self-connection brand affects the individual's decisions to enact goal consistent (versus inconsistent) choices.

As discussed in the previous section, "Basic elements of goal pursuit," when actively pursuing a desired end state or goal, self-regulation of behavior toward achieving a goal requires that individuals monitor their progress at different intervals for input on how much effort is needed to accomplish the goal and whether any adjustment to one's current behavior should take place (Carver \& Scheier, 1998). Typically, when a person believes that they are making adequate progress toward accomplishing a goal, this creates a sense of optimism. Individuals can rely on many different cues to signal to them that they are making progress toward a goal, such as judging recent behaviors that they have enacted as goal-consistent. Research has shown that perceived progress can have a detrimental effect when the individual relies on cues that signal a false sense of progress (Fishbach and Dhar, 2015). For example, when an individual has just engaged in a goal-consistent action (e.g., stayed up late studying for a test), the individual may view this action as a signal of progress toward the goal (i.e., being prepared for the test). A false sense of progress often leads people to infer that they will continue to make progress in the future (Fishbach and Dhar, 2005). This leads to overestimating their future progress, which 
encourages individuals to subsequently choose a goal-inconsistent behavior (i.e., going out to lunch with friends).

I propose that a high SBC brand could encourage maladjusted goal-directed behavior in specific contexts where the brand produces a false sense of progress. Brick and Fitzsimons (2017) found that individuals who are low in relationship power, instead of engaging in difficult and constructive conversations with their significant other, bought brands that are less liked by their partner to "get even" with them. This exemplifies the use of brands as a goal-inconsistent compensatory mechanism, in this case, to gain revenge on their relationship partner by purchasing their partners' disliked brands, rather than engaging in adaptive behaviors that help achieve the goal of improving the relationship. In this example, the consumer would likely perceive false progress and feel subsequently justified to engage in other goal-inconsistent choices (Fishbach and Dhar, 2005).

Additionally, brands with which consumers have high self-connection could hinder consumers' goal pursuits for a different reason. For example, goals are mental representations of the desired end state (Fishbach and Dhar, 2005), and consumers use brands to reach the ideal-self (Carver and Scheier 1998; Gollwitzer and Moskowitz 1996). Accordingly, consumers could perceive that merely buying a brand with which they have high-self connection as progress toward the goal, especially if this brand has strong symbolic associations with achievement of a goal such as an aspirational self-image goal (The best athletes buy Nike, therefore by buying Nike apparel I improve my athletic performance). Such perceived progress could also lead consumers to justify subsequent goal-inconsistent behavioral choices that could later demotivate goal striving. Thus, I hypothesize: 
H1: Consumers who are using high (low) self-brand connection are more (less) likely to make goal-inconsistent choices.

H2: Consumers who are using high (low) self-brand connection are more (less) likely to exaggerate their perceived degree of progress.

H3: Exaggerated progress mediates the relationship between self-brand connection and subsequent choices

In addition, given that individuals are motivated to approach positive resources associated with pleasure and avoid negative resources associated with pain (Markus \& Nurius, 1986; Strong \& Aron, 2006). I theorize that when consumers fail in a brand-assisted goal, they are more likely to distance themselves from the brand. This distance will weaken their psychological connection with the brand or self-brand connection. On the other hand, when consumers succeed in a brandassisted goal, they are more likely to increase their psychological connection with the brand, which will strengthen self-brand connection. Accordingly,

H4: Individuals who fail (succeed) in a brand-assisted goal purist are more likely to distance (associate) themselves from (with) the brand. Thus decreasing (increasing) their SBC.

Stronger (weaker) self-brand connection after the consumer monitors their progress will serve as a cue of their commitment to the brand-supported goal the consumer is pursuing. A 
stronger self-brand connection signals a high value of and the consumer's strong commitment to the brand-supported goal. In contrast, a weaker self-brand connection signals the low value of and weak commitment to the brand-supported goal. Inferring strong goal commitment motivates goal-consistent subsequent choices, whereas low goal commitment is demotivating and encourages goal-inconsistent subsequent choices (Zhang \& Huang, 2010). Thus, I hypothesize:

H5: Strong (vs. weak) updated self-brand connection is associated with greater (lower) likelihood of making goal-consistent subsequent choices.

H6: The consumer's post-goal progress SBC mediates the relationship between perceived progress and subsequent goal-consistent choice.

In sum, this dissertation research examines how consumers' self-brand connections impact their subsequent choices. I predict that pursuing a goal with the support of a high (versus low) self-connection brand will increase (decrease) the extent to which the individual will engage in goal-inconsistent behaviors (H1). The mechanism by which self-brand connection influences consumers' subsequent goal-(in)consistent choices is the consumers' perception of progress. Using a high (versus low) self-connection brand leads to a greater false sense of progress (H2) and this exaggerated perceived progress mediates the effect of self-brand connection on consumers' subsequent goal inconsistent choices (H3). A feedback loop is also expected to occur in which perceived goal progress failure (versus success) leads to decreased (increased) self-brand connection strength (H4), which subsequently decreases (increases) goal- 
consistent choice $(\mathrm{H} 5, \mathrm{H} 6)$. Thus, an asymmetric effect is anticipated in which initially high SBC strength negatively affects goal-consistent choice, yet subsequently higher SBC strength positively affects goal-consistent choice. 
Figure 2. Theoretical Framework

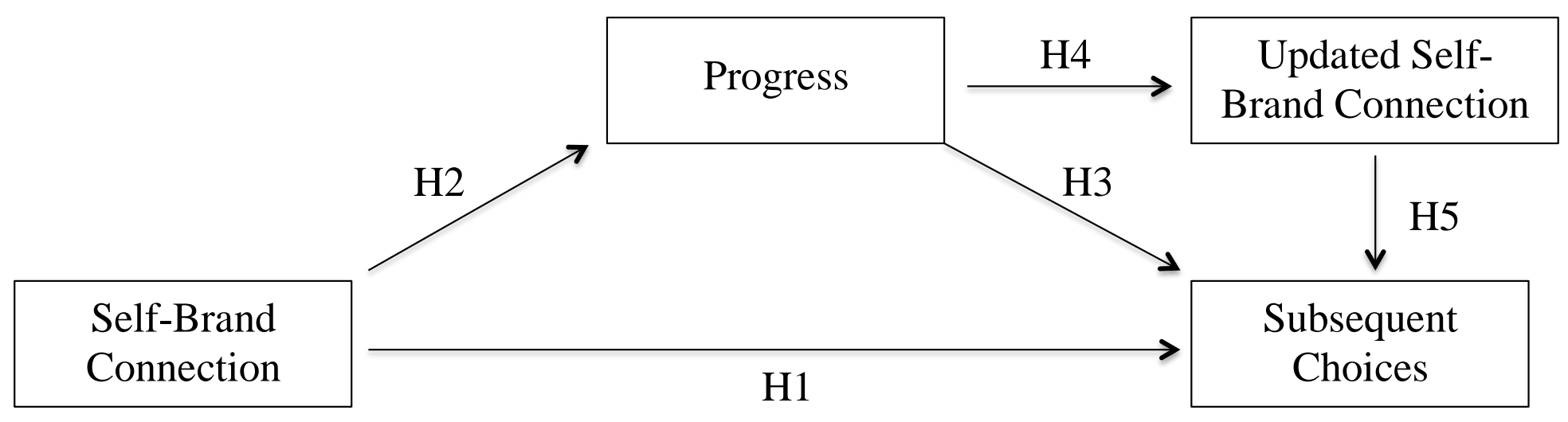




\section{Chapter 4: METHOD}

\section{Overview}

The objective of this set of studies was to test the hypotheses (H1-H6) that there will be a greater (lesser) positively-biased evaluation effect of strong (vs. weak) self-brand connection (SBC) on perceived goal progress, which will result in stronger SBC when goal progress is evaluated more (vs. less) positively), and will result in greater (vs. lesser) goal-consistent choices. Different paradigms were used across the four main studies, including fictional scenarios, engaging in a writing task, and solving anagrams. Both real and fictitious brands were used and self-brand connection was both measured and manipulated. To increase generalizability, the contexts were varied, including college exam preparation, improving athletic performance, improving physical fitness, charitable behavior, and improving cognitive

performance. A new method for manipulating self-brand connection strength was developed and pre-tested for Study 2. Study 3 and 4Given that all the studies used undergraduate student participants, the stimuli and contexts were designed for greatest relevance to the sample.

\section{Study 1}

Study 1 examines whether self-brand connection affects consumers'subsequent choices, such that when consumers are using brands with high self-connection, they are more likely to experience increased perceived goal progress. Thus, these consumers are more likely to make goal-inconsistent choices. On the other hand, consumers who are using brands with low selfconnection are less likely to perceive increased goal progress, thus making less goal-inconsistent choices. (H1-H3). 


\section{Participants and Design}

Study 1 is a self-brand connection (continuous measure) x 2 (Goal Type: Ideal vs. Ought) between subjects quasi-experimental design in which self-brand connection was measured and goal type was manipulated. Goal type was included as a potential boundary condition to observe whether SBC affects goal pursuit in ideal or "want to" -type goals, but not for ought or "have to" type goals. Perceived progress and subsequent choices were included as the key dependent variables. Eighty undergraduate students at FIU completed the study in exchange for extra credit.

\section{Procedure}

Participants completed the study in the behavioral research lab at individual computer stations separated by corrals. All stimuli and measures were administered using the Qualtrics web survey platform. The cover story told participants that this was a study about college student goals.

Participants in the ideal-goal condition were asked to read a hypothetical scenario in which they have to start working out to stay fit. The hypothetical scenario states that participants will be using an Apple Watch (adapted from Ferraro, Kirmani and Matherly, 2013) to enhance their workout routine. At the end of the hypothetical scenario, participants read, "After using the Apple Watch for six months, you noticed that you are fitter and your performance improved compared to six months ago." As for participants in the ought-goal condition, they read a hypothetical scenario in which they have to take a 50-question cumulative exam. The hypothetical scenario states that the course instructor will loan students an Apple iPad (adapted from Ferraro, Kirmani and Matherly, 2013) to enhance students' success. At the end of the 
hypothetical scenario, participants read "You checked your grade two weeks later and found that you got a good grade on the exam,"

Then participants were asked to write whatever thoughts came to their minds about the Apple Watch. Once they were done they were asked to complete the survey that included the three focal dependent variables and other relevant measures that were included for exploratory purposes. Last participants answered demographic questions.

\section{Measures}

Using seven-point likert-type scales, participants were asked to complete the self-brand connection scale (Esacalas and Bettman, 2003), which includes such items as: "Brand X reflects who I am," "I can identify with Brand X," "I (can) use Brand X to communicate who I am to other people." Participants were asked to rate on a seven-point scale their progress: $(7=$ no progress, $1=$ a lot of progress). To capture interest in pursuing incongruent activities, participants in the ideal-goal condition were asked to rate on a seven-point scale their interest in drinking a soda and eating a chocolate, and participants in the ought-goal condition were asked to rate on a seven-point scale their interest in hanging out with friends and watching Netflix: $(7=$ Extremely unlikely, 1 = extremely likely). (Adapted from Fishbach and Dhar, 2005). To capture interest in pursuing goal-consistent activities, participants in the ideal-goal condition were asked to rate on a seven-point scale their interest in eating an Apple and drinking spring water, and participants in the ought-goal condition were asked to rate on a seven-point scale their interest in studying and working on their coursework: ( 7 = Extremely unlikely, $1=$ extremely likely). (Adapted from Fishbach and Dhar, 2005). Participants then responded to demographic items. Upon completing the survey, participants were thanked and debriefed. 


\section{Results}

Two participants were removed from the analysis, as they did not complete the survey. Thus, the final sample consisted of 78 participants (females $=51$, males $=27$ ).

The tests of whether using brands with high (low) self-connection during goal striving leads to greater (lesser) likelihood of making goal-(in)consistent choices (H1), and increases (decreases) perceived progress $(\mathrm{H} 2)$, and whether perceived goal progress mediates these relationships (H3) were conducted using regression models in which perceived progress was the dependent variable and self-brand connection was the independent variable. Results of the analysis revealed no significant effects of self-brand connection on goal-inconsistent choices ( $p$ $=.59)$. However, to have a better understanding of consumers' goal pursuits, there's a need for goal-consistent choices to capture a more comprehensive goal pursuit behavior (e.g., Fishbach and Dhar, 2005). Accordingly, I measured participants' goal-consistent behavior. The results of the analysis revealed unexpected significant effect of self-brand connection on goal-consistent choices $(b=.230, t(76)=2.8, p<.01)$; consumers higher in self-brand connection are more likely to make goal-consistent choices than consumers who are lower in self-brand connection (see Table 2 and Figure 3 below).

In addition, supporting hypothesis 2 , results of the analysis revealed a significant effect of self-brand connection on perceived progress $(\mathrm{B}=.392, t(77)=3.6, p<.01)$; consumers higher in self-brand connection reported higher perceived progress than consumers who are lower in selfbrand connection (see Table 3 and Figure 4 below). 
Table 2. Regression Analysis Of The Effect Of Self-Brand Connection On Goal Consistent Choices (Study1)

\begin{tabular}{|c|c|c|c|c|c|}
\hline \multirow[t]{2}{*}{ Effect } & \multirow[t]{2}{*}{ Estimate } & \multirow[t]{2}{*}{$S E$} & \multicolumn{2}{|c|}{$95 \%$ CI } & \multirow[t]{2}{*}{$P$} \\
\hline & & & $L L$ & $U L$ & \\
\hline Constant & 4.26 & .302 & 3.66 & 4.86 & .000 \\
\hline Self-Brand Connection & .238 & .079 & .081 & .395 & .004 \\
\hline
\end{tabular}

Figure 3. How Self-Brand Connection Affects Goal-Consistent Choices

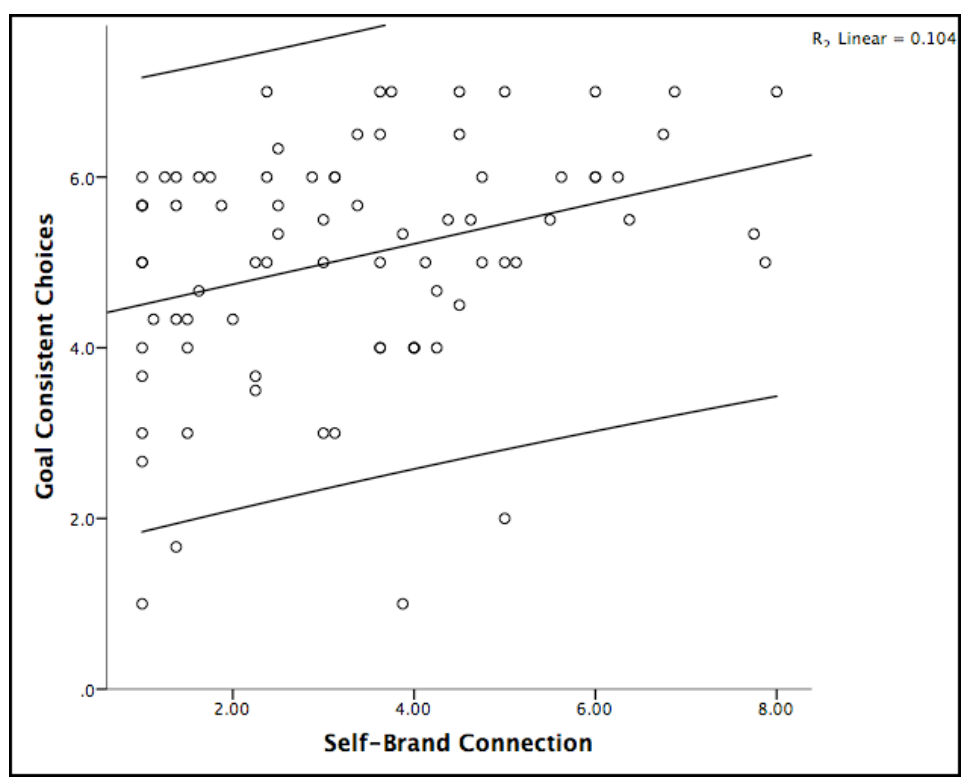


Table 3. Regression Analysis Of The Effect Of Self-Brand Connection On Progress (Study1)

\begin{tabular}{lccccc}
\hline \hline \multirow{2}{*}{ Effect } & Estimate & $S E$ & \multicolumn{2}{c}{$95 \%$ CI } & $P$ \\
\cline { 5 - 6 } & & & LL & UL & \\
\hline Constant & 3.63 & .396 & 2.84 & 4.26 & .000 \\
\hline Self-Brand Connection & .401 & .104 & .195 & .607 & .000 \\
\hline
\end{tabular}

Figure 4. How Self-Brand Connection Affects Perceived Progress

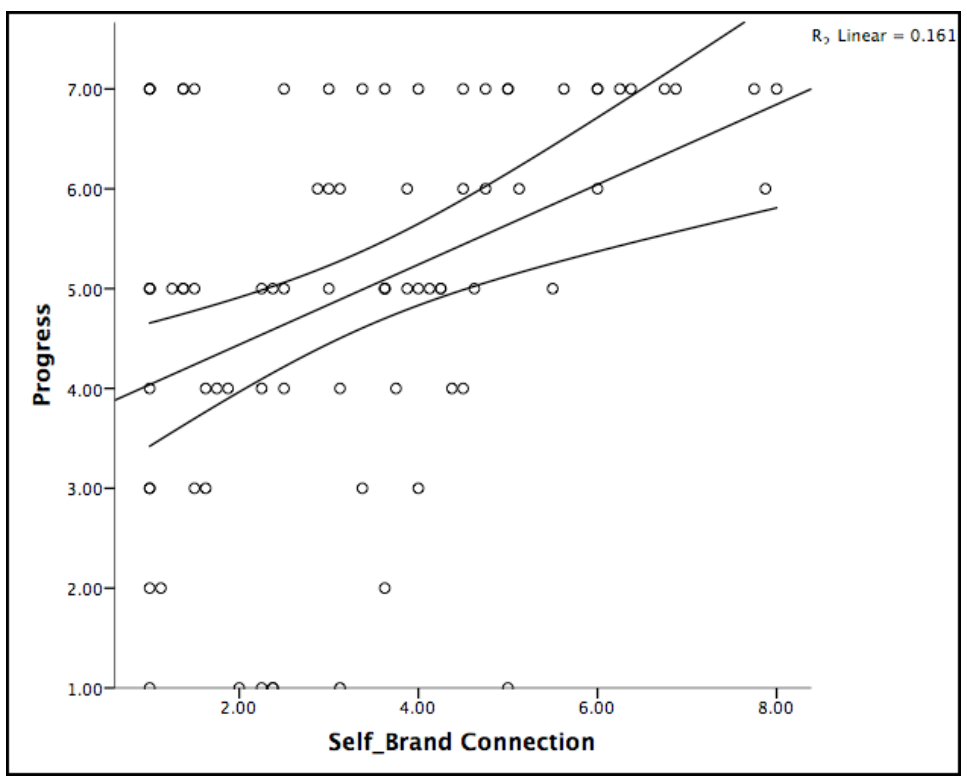


Mediation Analysis. Given the experiment's design, I predicted that perceived progress resulting from using a brand with high self-brand connection would lead consumers to justify goal-inconsistent choices. Accordingly, consumers who are using brands with high self-brand connection are more likely to make goal-inconsistent choices compared to those who are using brands with low self-brand connection. On the other hand, consumer's perceived lack of progress would motivate consumers who are using brands with low self-brand connection to make more goal-consistent choices.

As the analysis of the study demonstrated earlier, high self-brand connection lead consumers to make more goal-consistent choices. While the results did not support my hypothesis, I conducted a mediation analysis of the indirect effect of self-brand connection on goal-consistent choices through perceived progress using the Hayes macro for SPSS, model 4. While progress had a significant effect on goal-consistent choices $(\mathrm{B}=.161, \mathrm{t}(77)=2.02, \mathrm{p}<$ $.05)$, the mediation coefficient was not statistically significant $(B=0.24, p<0.2)$. Thus, hypothesis 3 was not supported.

I conducted further analysis to test if there is any relationship between the factors discussed earlier. Accordingly, I conducted a correlation analysis to investigate if there is any possible relationship, or a pattern, between self-brand connection, perceived progress and goalconsistent choices. There was a statistically significant correlation $(N=80)$ between perceived progress and goal-consistent choices, $r=.25, \mathrm{p}<.05$, perceived progress and self-brand connection $r=.40, p<.05$, and between self-brand connection and goal-consistent choices, $r=$ $.32, p<.05$. 
Table (4). Pearson correlations for Study1 variables

\begin{tabular}{lcc}
\hline \hline & $\begin{array}{c}\text { Self-Brand } \\
\text { Connection }\end{array}$ & Perceived Progress \\
\hline Perceived Progress & $.401^{*}$ & $.250^{*}$ \\
\hline Goal-Consistent Choices & $.323^{*}$ & \\
\hline Note. statistically significant at $p<0.05$ level &
\end{tabular}

\section{Discussion}

Study 1 provides initial evidence that self-brand connection determines, to a certain extent, consumers' subsequent choices during the goal pursuit. Specifically, consumers who are higher (vs. lower) in self-brand connections are more likely to make goal-consistent choices. Also, as hypothesis 2 predicts, consumers exaggerate their level of progress depending on the self-brand connection. However, study 1 did not provide any support for the effect of self-brand connection on goal-inconsistent choices, nor the mediation effect of perceived progress on selfbrand connection. Study $1 \mathrm{~b}$ has two objectives. The first is to manipulate the self-brand connection instead of measuring it. Also, subsequent choices will be measured differently. Instead of asking participants to rate on a scale their interest to make goal-consistent choices or goal in-consistent choices, participants will be asked to indicate their interest in disengaging from the focal goal and pursuing a different one. Fishback, Zhang and Koo (2009) argued that individuals could engage in goal in-consistent choices by trying to balance their efforts between a focal goal and a background goal and engage in goal consistent choices by highlighting and prioritize the focal goal. Accordingly, in study 1b, participants will be asked to indicate their 
interest in participating in a second activity (i.e., doing the dishes) beside the focal goal (i.e., improving their athletic performance in their chosen sport).

\section{Study 2}

\section{Pretest}

Given that a main objective of Study 2 was to manipulate self-brand connection instead of measuring it, I pretested a newly developed manipulation online using Qualtrics web survey software among a sample of forty-four undergraduate FIU marketing students wherein I asked participants to rank a list of personality traits, associated with Aaker's (1998) brand personality dimensions, by ranking the personality trait that represents them the most, and the personality trait that represent them the least. These personality traits included sincere, competent, masculine, feminine, and other brand personality traits. Then, participants were introduced to a fictional brand named "Zynox" which sells a wearable watch similar to Fitbit and Apple Watch that provide feedback and progress reports that would help users to improve their skills in their chosen sport (e.g., Basketball).

Participants were then asked to imagine a brand as a person with human traits and were provided the example of a Ford Mustang being described as "cool" and "sexy." Then, using Qualtrics' piping text feature, participants in the high (low) self-brand condition were shown a brief description of the brand that included the personality trait that represented them the most (least). Participants then completed the nine self-brand connection scale (Escalas and Bettman, 2005) items.

An independent-samples t-test was conducted to compare self-brand connection for participants in the low and high self-brand connection conditions. There was a significant 
difference in the scores for high self-brand connection $(\mathrm{M}=4.82, \mathrm{SD}=1.24)$ and low self-brand connection $(\mathrm{M}=3.54, \mathrm{SD}=1.05)$ conditions; $\mathrm{t}(42)=3.64, \mathrm{p}<0.01$. These results suggest that the manipulation succeeded in generating differential self-brand connection ratings toward the fictitious brand of wearable smart devices. Specifically, the results suggest that when the brand was described by the personality traits that represented participants the most (least), their selfbrand connection increased (decreased).

\section{Main study}

Participants and Design. Study 2 is a 2 (Self-brand connection: High vs. Low) x 2 (Goal-outcome: Success vs. Failure) between-subjects factorial design, in which both factors were manipulated. This study was designed to test whether high (versus low) self-brand connection increases (decreases) subsequent goal-consistent choices (H1) and leads to greater perceived progress ( $\mathrm{H} 2)$ and the extent that progress mediates the $\mathrm{SBC}-$ goal-consistent choice relationship (H3). Perceived progress and subsequent choices were included as the key dependent variables. One hundred forty one undergraduate students at FIU completed the study in exchange for extra credit.

Procedure. Participants completed the study in the behavioral research lab at individual computer stations separated by corrals. All stimuli and measures were administered using the Qualtrics web survey platform. The cover story told participants that this was a study about college students' goals.

After performing the self-brand connection manipulation described in the pretest, participants were asked to rank different tasks (i.e., second activity) and move the task they feel they need to do the most to the top of the list. The list included doing laundry, washing dishes, 
grocery shopping, and cooking dinner. Afterward, participants were informed that the first study was completed, and they will start the second study, which is about "athletic activity preferences."

The athletic activity preferences started with questions that measure their attitude towards different popular sports that were chosen based on a previous pretest such as basketball, golf, hockey, tennis, and jogging. And they were asked to write 5-7 ways in which they intend to try to improve their skills in their chosen sport. Then the cover story introduced a fictional brand named Zynox, a wearable device similar to Fitbit that will help them track their activity in the selected sport and provide important stats and tips regarding their performance. Then, participants went through the same procedure described in the pretest. After measuring goal commitment and intention to use the brand for exploratory reasons, participants were introduced with the goal-outcome manipulation. Participants in the success (failure) condition were informed in a hypothetical scenario that after using the product for a few weeks, they noticed great improvement (no improvement) in their skills and performance.

Then participants were asked to complete the survey that included the three focal dependent variables and other measures. Last participants answered demographic questions. Upon completing the survey, participants were thanked and debriefed.

Measures. Another factor that is different from study 1 is the way subsequent choices were measured. Instead of providing goal-inconsistent choices, in this study, I tried to capture how participants might disengage from the focal goal (i.e., improving their skills in a chosen sport) and engage in another activity instead (i.e., the second activity). 
Interest in pursuing goal-consistent activities. Participants were asked to rate on a sevenpoint scale their interest in analyzing the progress feedback and improvement tips they received from the Zynox brand to use them in their training instead of doing the second activity: ( 7 = Very unlikely, 1 = very likely).

Interest in pursuing goal-inconsistent activities. Participants were asked to rate on a seven-point their interest in doing the second-activity instead of analyzing the feedback from the Zynox brand: $(7=$ Extremely unlikely, $1=$ extremely likely $)$.

Dependent measures. The key dependent measures were perceived progress and selfbrand connection, which were measured similarly to study 1 .

Manipulation Checks. An independent-samples t-test was conducted to compare selfbrand connection for participants in the low and high self-brand connection conditions. There was a significant difference in the scores for high self-brand connection $(\mathrm{M}=3.61, \mathrm{SD}=1.49)$ and low self-brand connection $(\mathrm{M}=3.06, \mathrm{SD}=1.40)$ conditions; $\mathrm{t}(118)=2.04, \mathrm{p}<0.05$. These results suggest that the manipulation really does have an effect on self-brand connection. Specifically, our results suggest that when the brand was described by the personality traits that represent them the most (least), their self-brand connection increased (decreased).

Results. Twenty-one participants were removed from the analysis, as they did not pass the attention check question. Thus, the final sample consisted of one hundred and twenty participants (females $=70$, males $=50)$. A 2 (self-brand connection: high vs. low) $\mathrm{x}$ (goal outcome: success vs. failure) ANOVA was conducted and the interaction effect did not reach significant level $(\mathrm{p}=.844)$. However, the analysis showed a significant main effect of self-brand 
connection on goal-consistent choices similar to the results found in study 1 . Participants in the high self-brand connection condition $\left(M_{h i g h}=5.99\right)$ reported higher interest in evaluating the feedback from the Zynox brand to improve their athletic performance (i.e., the focal goal) compared to those in the low self-brand connection condition $($ Mlow $=5.14) ;(F(1,116)=4.21, p$ $=0.032$ ). Another 2 (self-brand connection: high vs. low) x 2 (goal outcome: success vs. failure) ANOVA was conducted to test the effect of self-brand connection and goal outcome effect on goal-inconsistent choices (i.e., doing the second activity instead of using the feedback to improve their athletic performance) and the interaction effect did not reach significant level $(p=.931)$, and there was no significant main effect (see Table 4 and Figure 5).

Table 4. ANOVA Analysis Of The Effect Of Self-Brand Connection On Goal Consistent Choices (Study 2)

\begin{tabular}{|c|c|c|c|c|c|c|}
\hline \multirow[t]{2}{*}{ Measure } & \multicolumn{2}{|c|}{ High SBC } & \multicolumn{2}{|c|}{ Low SBC } & \multirow[t]{2}{*}{$F(1,116)$} & \multirow{2}{*}{$\begin{array}{c}\text { Partial Eta } \\
\text { Squared }\end{array}$} \\
\hline & $M$ & $S E$ & $M$ & $S E$ & & \\
\hline Goal Consistent Choices & 5.92 & .27 & 5.14 & .23 & 5.29 & .028 \\
\hline
\end{tabular}


Figure 5. How Self-Brand Connection Affects Goal Consistent Choices (Study 2)

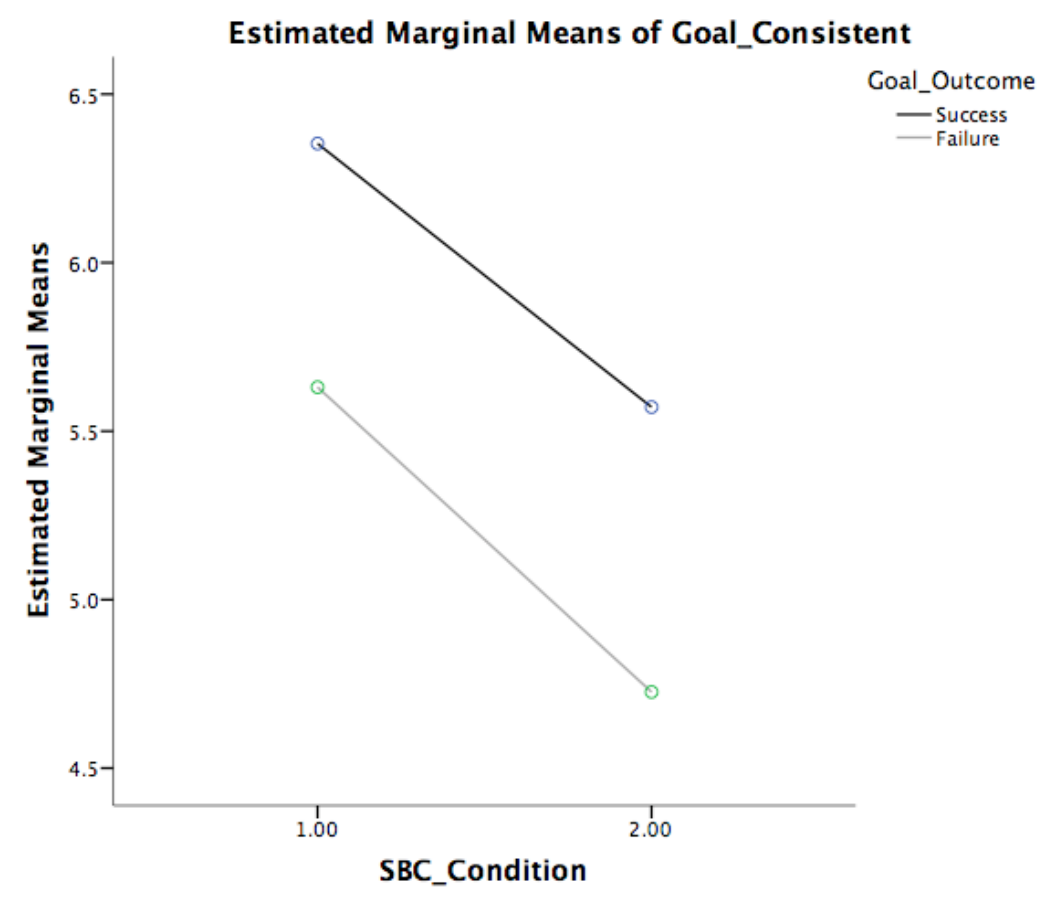

As for hypothesis 2, self-brand connection did not had an effect on perceived progress ( $\mathrm{p}$ $>$.05) thus hypothesis 2 was not supported. Accordingly, I did not conduct a mediation analysis to test hypothesis 3 .

Discussion. Study 2 replicated only one significant effect from study 1 , which is the effect of self-brand connection on subsequent choices. However, there was no significant effect of self-brand effect on progress. Besides the likelihood that there's no significant effect, to begin with, another possible explanation is how progress was measured in the previous two studies. Perceived progress is more likely to be an implicit process, and reliable and valid measurement of implicit attitudes remains a challenge (e.g., Brendl et al. 2001; Greenwald, McGhee, and Schwartz, 1998). Accordingly, in the last study, progress will be measured by comparing 
participants' moods before and after reading about their level of progress (Carver \& Shier, 2014). This issue will be considered in study 4 .

In study 3, I seek to provide evidence for the effects of goal-outcome on self-brand connection. Accordingly, the consumer-brand connection will be measured after the goaloutcome

\section{Study 3}

Study 3 examines whether goal outcome affects self-brand connection, such that when consumers fail (vs. succeed) in a brand-assisted goal pursuit they are more likely to distance (associate) themselves from (with) the brand (H4).

\section{Participants and Design}

Participants were 458 undergraduate students at (FIU) who participated in exchange for extra credit. The experiment used a 2 (Goal outcome: failure vs. success) x 2 (self-brand connection: High vs. low) between-subject factorial design.

\section{Procedure}

Participants completed the study in the behavioral research lab at individual computer stations separated by corrals. All stimuli and measures were administered using the Qualtrics web survey platform. The cover story told participants that this was a study about college students' goals.

First, participants in the high self-brand connection were asked to write 5 Apple brand personality traits that they want to be connected with their self-concept or view of themselves. 
As for participants in the low self-brand connection, they were asked to write 5 Apple brand personality traits that they do not want to be connected with their self-concept or view of themselves. Then, participants read a hypothetical scenario similar to the one used in the previous study (i.e., using an Apple Watch to stay fit). Participants in the success condition read at the end of the hypothetical scenario: "After using the Apple watch for six months, you notice that you are fitter and your performance improved compared to six months ago." As for participants in the failure condition, they read at the end of the hypothetical scenario: "However,

after using the Apple watch for six months, you notice that you are less fit and your performance worsened compared to six months ago.” After reading the hypothetical scenario, participants were asked to describe how the Apple Watch contributed to their weight loss goal success or failure, depending on their condition. Afterward, participants answered questions that measure their self-brand connection.

\section{Independent Variables}

Goal. Goal was manipulated using the same hypothetical exam scenario used in Study 1 (i.e., using an Apple Watch to stay fit).

Goal Outcome. At the end of the hypothetical scenario, participants in the success condition were asked to read: "After using the Apple watch for six months, you notice that you are fitter and your performance improved compared to six months ago." As for participants in the failure condition, they read at the end of the hypothetical scenario: "However, after using the Apple watch for six months, you notice that you are less fit and your performance worsened compared to six months ago." 
Self-brand connection. Self-brand connection was measured using the Self-brand Connection Scale (Escalas and Bettman, 2005).

\section{Manipulation Check}

An independent-samples t-test was conducted to compare self-brand connection for participants in the low and high self-brand connection conditions. There was a significant difference in the scores for high self-brand connection $(\mathrm{M}=3.55, \mathrm{SD}=1.57)$ and low self-brand connection $(\mathrm{M}=3.08, \mathrm{SD}=1.46)$ conditions; $\mathrm{t}(457)=3.2, \mathrm{p}<0.01$. These results suggest that the manipulation really does have an effect on self-brand connection. Specifically, our results suggest that when participants wrote about the similarity between Apple brand and their own personality traits, their self-brand connection increases.

\section{Results}

An independent samples t-test was used to test whether consumers who perceive progress failure in a brand-assisted goal pursuit are more likely to distance themselves from the brand, whereas individuals who perceive goal progress success in a brand-assisted goal pursuit are more likely to associate (distance) themselves with (from) the brand (H4). Supporting hypothesis 4, an independent-samples t-test revealed that there was a significance difference between participants in the high self-brand connection and those in the low self-brand connection condition $(M$ success $=$ $\left.3.54, M_{\text {failure }}=3.11 ; t(1,457)=32.9, p<.01\right)($ see Table 5$)$. 
Table 5. Independent Samples Test Of The Goal Outcome Effect On Self-Brand

Connection (Study 3)

\begin{tabular}{|c|c|c|c|c|c|c|}
\hline \multirow[t]{2}{*}{ Measure } & \multicolumn{2}{|c|}{ SUCCESS } & \multicolumn{2}{|c|}{ FAILURE } & \multirow[t]{2}{*}{$T(1,457)$} & \multirow[t]{2}{*}{$p$} \\
\hline & $M$ & $S D$ & $M$ & $S E$ & & \\
\hline SELF-BRAND CONNECTION & 5.94 & 1.4 & 3.11 & 1.6 & 32.9 & .003 \\
\hline
\end{tabular}

\section{Discussion}

Study 3 provides initial evidence that goal-outcome does affect self-brand connection. In the next study, I investigate how the change in self-brand connection might influence subsequent choices, and wither progress mediates the relationship between the updated self-brand connection and subsequent choices.

In the previous two studies, study 1 and study 2 , there were significant effects of selfbrand connection on subsequent choices and perceived progress. But the results did not support hypothesis 3 , which states the progress drives the effect of self-brand connection on subsequent choices. Accordingly, in this study I added other measures such as perceived goal difficulty, goal commitment, and attitude toward the brand were included for explanatory purposes. An independent samples t-test revealed a significant effect of self-brand connection on perceived goal progress, and there was a significant difference in the scores for high self-brand connection $(\mathrm{M}=4.25)$ and low self-brand connection $(\mathrm{M}=3.89)$ conditions; $\mathrm{t}(457)=2.17, \mathrm{p}<0.01$. This result suggests that participants who have a higher self-brand connection with the brand reported higher perceived goal difficulty compared to those who have a lower self-brand connection. Such results deserve further investigation to understand what is driving this effect. 


\section{Study 4}

\section{Participants and Design}

Study 4 used a mixed 2 (self-brand connection: high vs. low) x 2 (goal progress: low vs. high) x 2 (affect: pre-task vs. post-task) x 2 (updated self-brand connection: pre-task vs. posttask) between- and within-subjects design. Self-brand connection and goal progress were between subjects, manipulated factors. Affect and updated self-brand connection were both within subject, measured factors. Subsequent choice was a dependent variables. Eighty-five marketing undergraduates from Florida International University completed the study in exchange for extra-credit.

\section{Stimuli}

The stimulus product for this study was a brand of pens that supposedly helps with cognitive performance. This stimulus was adapted from Kim and Gal (2014). Students were given an actual physical pen to write with. A largely unknown brand of pens was chosen, TANMIT. A pre-test confirmed that familiarity with the brand name was below neutral.

Given that the brand of pens was TANMIT, this is the brand name that was used in the manipulation. All participants read a description of the pen that stated:

For the benefit of your anagram task performance, we will provide you with a specialized TANMIT Limited Edition Brain Pen for a smooth writing experience that will enhance the connection between your cognitive problem solving abilities and the mechanics of writing the anagram solutions. 
Then, on the next screen all participants read:

TANMIT's Limited Edition Brain Pen is the result of a collaboration with neurologist Dr. Richard Restak, MD. The elaborate rollerball pen consists of an ergonomic comfort grip that is scientifically shown to enhance comfort and confidence in writing, a reliable flow of organic-based gel ink, and a precisely designed $0.5 \mathrm{~mm}$ fine point tip 0.5 for optimal transcribing of your thoughts from your mind to the page. The magnetic silver alloy cap, core, and tip of the TANMIT Brain Pen promotes blood flow to the brain for improved cognitive processing capacity.

Participants then rated the extent to which using the TANMIT Brain Pen will help students perform well in the anagram task $(1=$ definitely will not; $9=$ definitely will). A onesample t-test was conducted with the scale neutral point (5) as the comparison point and the result was statistically significant $\mathrm{t}(78)=-3.5, \mathrm{p}<.001$. However, the mean $(\mathrm{M}=4.0)$ was below the scale neutral point, which indicates that, on average, participants did not view the TANMIT Brain Pen as supporting their goal of performing well on the anagram task.

\section{Manipulations}

Self-brand connection. For the self-brand connection manipulation procedure, participants ranked the brand personality traits from the options provided that described them best (high self-brand connection condition) or least (low self-brand connection condition). Then, using the Qualtrics piping text feature, participants in the high (low) self-brand condition were 
shown a description of the brand that used the brand personality traits they had previously ranked as representing them the most (least).

Goal striving mindset. The main goal pursuit task participants would have to complete is directly connected with the study's cover story of college assessment performance. The screen showed them this description of the cover story:

\section{New Tools for Universities Ranking}

QT University Ranking, the global authority in education rankings, started a new ranking that evaluates students' creativity, comprehension and critical thinking through different tests and cognitive assessment procedures. One of these tasks assesses creative problem solving through an anagram task.

Our goal today is to validate the effectiveness of the anagram task portion of the education ranking test. In a few moments you will be given a set time window to perform the task and your results will be compared to a global database of college student performance on this task.

FIU's rankings on this assessment will partly determine whether and how much funding the university receives for student scholarships.

Next, participants responded to an item that asked how important participating in this campus wide assessment task is to them ( $1=$ Not at all important; $5=$ Extremely important $)$. A one-sample t-test was conducted comparing the average rating to the scale neutral point (3). The result was statistically significant, $\mathrm{t}(79)=2.9, \mathrm{p}<.01$ and the mean $(\mathrm{M}=3.31)$ was higher than the 
neutral point. This indicates that participants did perceive their performance on this assessment as an important goal for themselves. Thus, participants were successfully induced into a goal striving mindset.

In conjunction with the QT University Rankings cover story, the next part of the goal striving induction involves the anagram solving task. The instructions given for this task began with the text below on the first screen, followed by additional directions to underscore the goal (see Appendix A for the full set of instructions shown to participants):

The QT Ranking problem solving task is next. You will be unscrambling sets of letters to form (correctly spelled) words. This is known as an ANAGRAM puzzle and involves problem solving skills.

Your goal is to solve at least 5 anagrams. This is the number the average college student is able to solve in two minutes. You will also have a 2-minute timer.

If you are successful by correctly solving at least 5 anagrams within 2-minutes, you will earn 2 Scholar dollars to use to purchase snacks from the new Scholaris Cafe downstairs in the CBC Lobby.

After reading all anagram task instructions, participants rated their desire to solve at least five anagrams using two nine-point semantic differential scale items $(1=$ Very weakly/9=Very strongly; $1=$ Not at all $/ 9=$ Very much). The two items were averaged to form a single index. A one-sample t-test was conducted comparing the average rating $(M=7.1)$ to the scale midpoint of 
5. The result was statistically significant, $\mathrm{t}(84)=8.4, \mathrm{p}<.001$. This indicates that participants strongly desired to achieve the goal of completing five anagrams in two minutes.

Goal progress. Perceived goal progress was manipulated by the difficulty of the task participants would have to perform. The anagram task either had many easy to solve scrambled word sets, or it had only three solvable anagrams (see Appendix B). Participants in the high goal progress condition received the anagram task that made it possible to fulfill the goal of solving at least five anagrams in two minutes, whereas those in the low goal progress condition received the anagram task that made it impossible to fulfill the goal because only three out of ten anagrams were solvable.

\section{Procedure}

Participants completed the study in the behavioral research lab at individual computer stations separated by corrals. All stimuli and measures were administered using the Qualtrics web survey platform. Only the anagram task was provided as a pen and paper task. However, the anagram task itself did not contain any dependent measures. The cover story told participants that this was a study about college assessment performance.

To induce a goal-striving mindset, participants read a cover story about a campus-wide assessment where a fictional institution (i.e., QT University Ranking) started a new ranking that evaluates students' creativity, comprehension, and critical thinking through different tests and cognitive assessment procedures. One of these tasks is an anagram task that they would be performing during the session. 
Then participants read the instructions for the anagram task (form real words using 2 or more of the letters in each set of scrambled letters). They were then informed that their goal was to solve at least five anagrams in two minutes given that this is the average global college student performance level.

Next, participants were informed that to assist them with their anagram test performance, that the university was going to provided them with a specialized limited edition brain pen (adapted from Kim and Gal, 2014).

Then the focal dependent variables were administered. Participants' self-brand connection and affect were measured twice-before and after the anagram task. The difference in mood is an implicit measure of progress (Carver \& Shier, 2014). In addition, self-brand were measured before and after participants viewed the description of their level of progress to test Hypothesis 4.

After reading the brand description and a reiteration of the goal, participants were given a sheet of paper containing the anagram task. As they solved the anagrams, their computer screen showed them the goal, to solve five anagrams in 2 minutes, and the reward, which is two units of behavioral lab currency ("scholar dollars") to buy snacks.

After measuring their affect and self-brand connection for the second time, participants were asked to report how many anagrams they solved and then their perceived progress. Subsequent choice was measured by asking participants to what extent they feel they desire to continue working on the anagram task. Also, subsequent choices were measured again by asking them about their desire to continue solving anagrams. Lastly, participants answered demographic questions, were thanked, and debriefed. 


\section{Measures}

Goal Importance. Participants were asked to rate on a five-point scale goal importance: (5= Extremely important, $1=$ Not at all important $)$. Also, participants were asked to rate on two nine-point semantic differential scales their desire to solve 5 anagrams $(9=$ very strongly, $1=$ very weakly; $1=$ Not at all/ $9=$ Very much).

Intent to use the brand. Participants were asked to rate on a nine-point scale their desire to use the brand: ( $9=$ definitely will, $1=$ definitely will not; $9=$ completely, $1=$ not at all).

Self-brand connection. The Self-brand Connection Scale (Escalas and Bettman, 2005) was rated on an eight-point scale (1=Very strongly disagree; $8=$ Very strongly Agree).

Affect. The items used to measure participants' pre- and post-task affect were adapted from Carver and Scheier (1998). Using bipolar seven-point scales, participants were asked to rate how they feel: $(1=$ despondent $/ 7=$ blissful; $7=$ delighted, $1=\operatorname{dejected}, 7=$ happy, $1=\operatorname{sad})$

Self-reported goal performance. A single item asked participants to report the number of anagrams they had completed at the end of the allotted time ("How many anagrams did you solve?"). The options were: $1,2,3,4,5$, more than 5.

Perceived goal progress. A single item explicitly measured perceived goal progress toward the goal of correctly solving at least 5 anagrams in response to the stem "The degree of progress I made is" using a visual slider scale ranging from 0 (None at a 1l) to 100 (A great deal).

Goal-consistent choices. Participants were asked to rate, using two seven-point bipolar scale items, $(7=$ completely $/ 1=$ not at all; $7=$ very strong desire $/ 1=$ very weak desire $)$ their interest to continue working on the anagram task if given the opportunity. Also, in a binary option, participants were asked to choose one of two options: "I want to continue solving anagrams" and "I am done solving anagrams". 


\section{Results}

Manipulation Check. An independent samples t-test was conducted to compare the pretask self-brand connection ratings for participants in the low and high self-brand connection conditions. There was a significant difference in the scores for high self-brand connection $(M=4.0)$ and low self-brand connection $(M=3.1)$ conditions; $\mathrm{t}(83)=-2.6, p<.05)$. These results suggest that the manipulation does have an effect on self-brand connection. Specifically, our results suggest that when participants read a brand description that matches (mismatches) their personality traits, their self-brand connection increases (decreases). Additionally, a one-sample ttest conducted just with the high self-brand connection group comparing the group's mean $(\mathrm{M}=4.0)$ self-brand connection rating to the scale neutral point (4.5) was not statistically significant, $\mathrm{t}(41)=-1.9, \mathrm{p}>.06$. This indicates that in the high self-brand connection condition, the average self-brand connection rating did not differ significantly from the scale neutral point. Thus, this condition represents, on average, an SBC relationship of neither weak, nor strong selfconnection to the TANMIT brand.

Self-reported goal performance. Participants rated how many anagrams they had actually solved. An independent samples t-test was conducted comparing the number of anagrams reportedly solved in the low $(M=5.4)$ versus high progress $(M=5.7)$ conditions. The results showed that the difference was not statistically significant, $\mathrm{t}(78)=-1.2, \mathrm{p}>.2$. Additionally, a frequency analysis of the low versus high progress condition self-reported performance showed that in both the high progress and the low progress condition, whose anagram task only had two solvable anagrams, $82 \%$ of participants reported completing 5 or more than 5 anagrams. Thus, it seems that the self-reports were influenced by socially desirability bias. 
Perceived goal progress. After completing the anagram task participants completed a measure of perceived progress that asked how much progress they felt they had made toward the goal of correctly solving at least 5 anagrams. Responses were provided on a visual sliding scale that ranged from 0 (none at all) to 100 (a great deal). An independent samples t-test was conducted between the low $(M=64)$ versus high progress $(M=64)$ participants perceived progress ratings. There was no significant difference between the low versus high progress group's perceived progress ratings $(t(74)=-.06, p>.9)$. This indicates that participants in the low versus high progress groups did not perceive any difference in their rate of progress toward the goal of completing at least five anagrams in two minutes even in spite of the impossibility of solving more than 2 anagrams correctly in the low progress condition anagram task. This result, once again, points to a social desirability bias in participants' progress ratings, given the aboveaverage progress ratings of 64 out of 100 in both conditions.

Hypothesis tests. First to test whether SBC affects subsequent choice (H1), an independent samples t-test was conducted with SBC condition as the independent variable and goal-consistent choice desire as the dependent variable.

Second, to test whether self-brand connection affects perceived goal progress as predicted by $\mathrm{H} 2$, a repeated measures ANOVA was conducted with pre-task and post-task affect as the within-subject independent variable, and self-brand connection condition and goal progress condition as between subject independent variables. The only significant effect was due to the Goal progress condition $x$ Affect interaction, $F(1,80)=11.3, p<.001$. The result showed that for participants in the high progress condition, affective ratings after the task $(M=5.5)$ were significantly more positive at the end of the task relative to the before the task started (M=5.1), $t$ 
$(40)=-4.6, p<.001$. However, for participants in the low progress condition, their affective ratings before the task started $(M=5.2)$ did not differ significantly from their affective ratings after the task $(\mathrm{M}=4.9), \mathrm{t}(42)=1.5, \mathrm{p}>.1$. These results are consistent with the notion that goal progress yields increased positive affect when an individual perceives that they have made goal progress (Carver and Scheier, 1998). However, the results do not support that SBC affects perceived progress according to this affect-based implicit goal progress perception measure.

Next, a 2 (SBC: low vs. high) x 2 (goal progress: low vs. high) univariate ANOVA was conducted with the explicit goal progress measure as the dependent variable. None of the effects were significant. Based on the set of hypothesis tests just described, hypothesis 2 was not supported.

Although these tests of the SBC-perceived progress relationship were not significant, the study design still allows me to test the indirect effect of SBC through perceived progress (H3) given that progress was a manipulated factor. The test involves three variables, SBC condition, progress condition, and subsequent choice, all which are dichotomous. The subsequent choice variable consists of the choice to continue working on the anagram task (goalconsistent) or to not work on the task further (goal-inconsistent). Thus, non-parametric statistical analysis is necessary to examine whether the joint influence of SBC and goal progress hypothesized in H3 is statistically significant. Support for the hypothesized effect in $\mathrm{H} 3$ requires results that show that high (low) SBC in connection with high progress demonstrates significantly more goal-inconsistent (goal-consistent) choices.

To this end, a cross-tabulation was conducted first (see Table 6) to obtain the observed number of cases in each cell, which facilitates visualizing the nature of the interaction effect. Next, a step-wise binary logistic regression analysis was conducted with the binary subsequent 
choice measure as the dependent variable and SBC condition and progress condition entered in step 1, and the product of these two variables (the interaction variable) entered in step 2 (see Table 7 for regression results).

Table 6. Cross-tabulation of SBC condition $x$ Progress condition $x$ Subsequent choice

\begin{tabular}{|c|c|c|c|c|}
\hline & \multicolumn{2}{|c|}{ Low SBC Condition } & \multicolumn{2}{c|}{ High SBC Condition } \\
\hline & $\begin{array}{c}\text { Low progress } \\
\text { condition }\end{array}$ & $\begin{array}{c}\text { High progress } \\
\text { condition }\end{array}$ & $\begin{array}{c}\text { Low progress } \\
\text { condition }\end{array}$ & $\begin{array}{c}\text { High progress } \\
\text { condition }\end{array}$ \\
\hline $\begin{array}{c}\text { Goal-consistent } \\
\text { choice }\end{array}$ & 2 & 8 & 6 & 5 \\
\hline $\begin{array}{c}\text { Goal-inconsistent } \\
\text { choice }\end{array}$ & 19 & 11 & 15 & 13 \\
\hline
\end{tabular}

Table 7. Stepwise binary logistic regression results

Step 1 coefficients

\begin{tabular}{llllllllll}
\hline \multicolumn{10}{c}{ Variables in the Equation } \\
\hline \hline
\end{tabular}

a. Variable(s) entered on step 1: SBCcond, progresscond.

\section{Step 2 coefficients}

\section{Variables in the Equation}

\begin{tabular}{|c|c|c|c|c|c|c|c|c|c|}
\hline & & \multirow[b]{2}{*}{ B } & \multirow[b]{2}{*}{ S.E. } & \multirow[b]{2}{*}{ Wald } & \multirow[b]{2}{*}{ df } & \multirow[b]{2}{*}{ Sig. } & \multirow[b]{2}{*}{$\operatorname{Exp}(B)$} & \multicolumn{2}{|c|}{ 95\% C.I.for EXP(B) } \\
\hline & & & & & & & & Lower & Upper \\
\hline \multirow[t]{4}{*}{ Step $1^{\text {a }}$} & SBCcond(1) & 1.335 & .887 & 2.268 & 1 & .132 & 3.800 & .669 & 21.598 \\
\hline & progresscond(1) & 1.933 & .877 & 4.861 & 1 & .027 & 6.909 & 1.239 & 38.516 \\
\hline & SBCxProg & 1.972 & 1.131 & 3.041 & 1 & .081 & 7.185 & .783 & 65.921 \\
\hline & Constant & -1.017 & 1.001 & 1.031 & 1 & .310 & .362 & & \\
\hline
\end{tabular}

a. Variable(s) entered on step 1: SBCXProg. 
For step 1, the Hosmer-Lemeshow (HL) fit statistic was non-significant, $\chi_{2}(2)=3.2, p=.2$, which indicates that the observed model fits well with the expected model and is, thus, not a poor fit model. The R-square prior of the model containing just SBC condition and progress condition is .05 , which increased to .11 after entering the interaction variable. This indicates that the SBC $\mathrm{x}$ progress interaction significantly adds explanatory value to the model. The HL fit statistic pvalue also increased in step $2, \chi_{2}(2)=0, p=1.0$, which is desirable and indicates good fit. Next, I examined the beta coefficients for the variables in the equation. The progress condition variable was significant and the interaction variable was significant. A graph of the cross tabulation of SBC condition $\mathrm{x}$ progress condition $\mathrm{x}$ subsequent choice is shown in Figure 6 to assist with visualizing the nature of the interaction.

Figure 6. Graphs: SBC condition $x$ Progress condition $x$ Subsequent choice

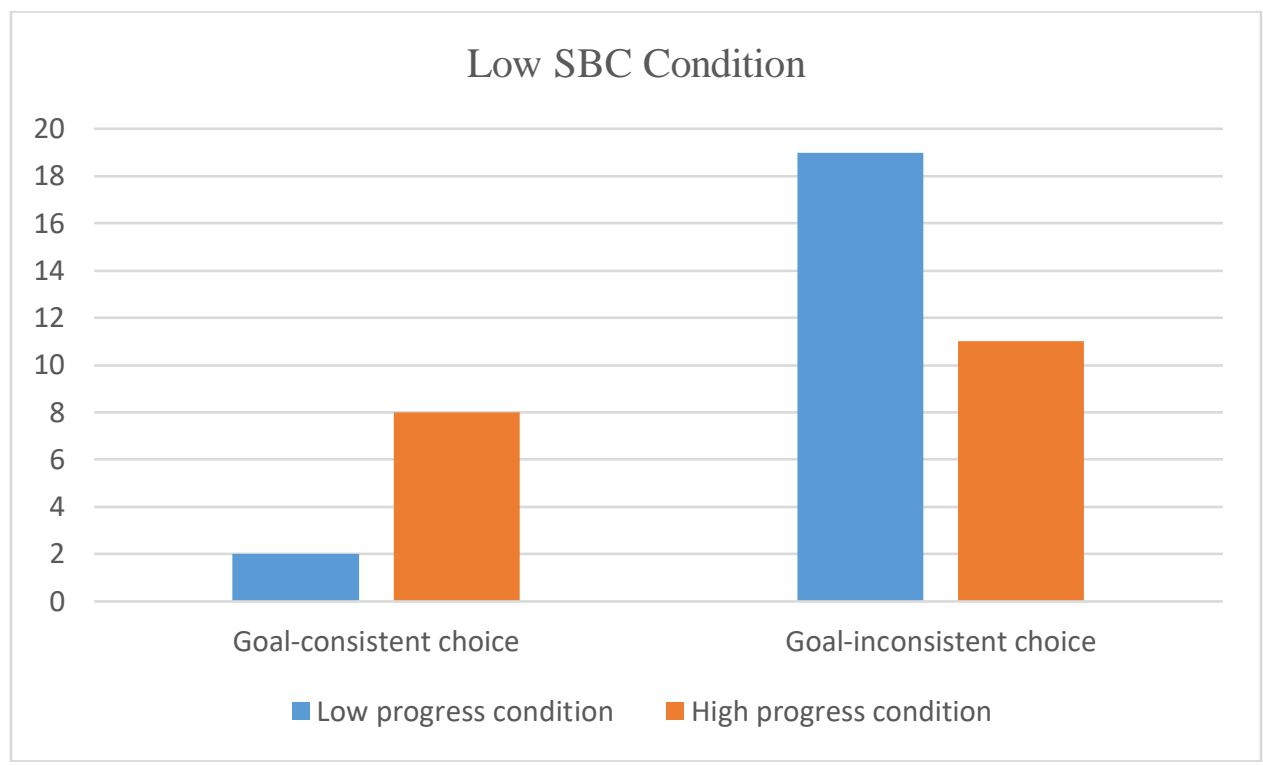




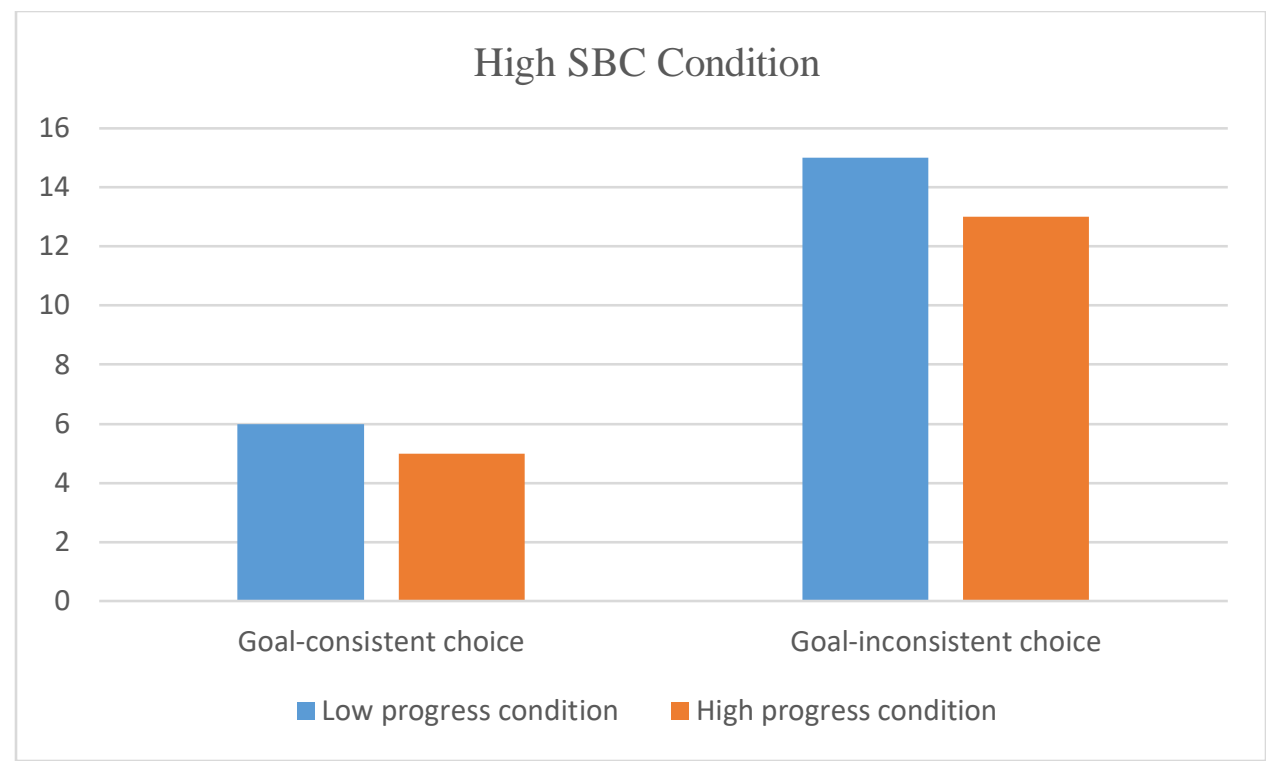

To probe the nature of the interaction effect, simple effects analyses were conducted using chi-square analyses of the relationship between progress and subsequent choice at each level of SBC. The results show that when SBC is low, progress and subsequent choice are significantly associated, given that the chi-square statistic is significant, $\chi^{2}(1)=5.6, p<.05$. As Figure 6 illustrates, high progress leads to more goal-consistent choices $(42.1 \%)$ than low progress $(9.5 \%)$ and low progress leads to more goal-inconsistent choices $(90.5 \%)$ than high progress $(57.9 \%)$. This is consistent with $\mathrm{H} 3$.

The results also show that when SBC is high, progress and subsequent choice are not significantly associated, $\chi_{2}(1)=.003, \mathrm{p}>.6$. In this condition, both low and high progress participants chose the goal-inconsistent option in greater proportion (Plow progress $=71.4 \%$; Phigh progress $=72.2 \%)$ than the goal-consistent option $\left(\mathrm{P}_{\text {low progress }}=28.6 \%\right.$; Phigh progress $\left.=27.8 \%\right)$. This result does not support H3. Taken together, the results support H3 partially. 
Results discussion. Study 4 had many limitations that may have contributed to the lack of support for $\mathrm{H} 1-\mathrm{H} 3$. There seems to have been social desirability bias surrounding the progress ratings and self-reported task performance measure that resulted in extremely high ratings across all conditions. This is likely due to the intensity of the cover story, which involved statements about FIU scholarship funding being dependent on the task performance. Also, although ratings of goal importance and desire to achieve the goal were high, ratings of how well the pen would help with task performance were also relatively weak, which indicates that participants were in a goal striving mindset, yet not strongly in a brand-assisted goal striving mindset.

\section{Discussion}

Ever since self-brand connection was first examined there was a lack of clarity to its specific definition. MacInnis and Folkes (2016) argue that the precise meaning of self-brand connection is "a bit elusive," and has "definitional issues" with the precise meaning of the construct. Indeed, researchers studying self-brand connections had different definitions of the construct. Self-brand connection could refer to the congruity between the self and the brand (e.g., This car is so me!; Chaplin \& John, 2005), the overlap between one's identity and the brand (e.g., Park, MacInnis, Priester, Eisingerich, \& Iacobucci, 2010; Park, Eisingerich, and Park, 2013a), or the inclusion of the brand as part of the self-concept (e.g., Reimann \& Aron, 2009). It was one of the main objectives of this dissertation to offer a better understanding of the construct and its influence on consumer behavior during the goal pursuit.

To have a better understanding of the self-brand connection construct, this dissertation used a theoretical model adapted from the goal literature (Bagozzi and Dholakia, 1999) for two reasons. First, to study the interaction between consumers and the brands they are using during 
different stages of the goal pursuit in a dynamic manner. Kopetz, Kruglanski, Arens, Etkin and Johnson (2012) argue that motivational research lacks a "wider" and "more dynamic" approach to study goals in general. Thus in this dissertation, I tried to solve this issue by examining the influence of self-brand connection during different stages of the goal pursuit on different constructs such as perceived progress, subsequent choices, and goal difficulty. Second, using a theoretical model adapted from the goal literature provides a focused approach to study constructs such as perceived progress, which could have different effects on self-brand connection during different stages of the goal pursuit thus lead to inconsistent, or even misleading results.

According to MacInnis and Folkes (2016), most papers operationalized the construct in a similar manner, using items such as "this brand represents me well" and "I feel that the brand reflects me" (e.g., Chaplin \& John, 2005; Escalas \& Bettman, 2003, 2005; Park et al., 2010, 2013a). Accordingly, in this dissertation, the self-brand connection construct was operationalized differently across four studies and two pre-tests. Different paradigms were used across the four main studies, including fictional scenarios, engaging in a writing task, and solving anagrams. To increase generalizability, the contexts were varied, including college exam preparation, improving athletic performance, improving physical fitness, charitable behavior, and improving cognitive performance. A new method for manipulating self-brand connection strength was developed and pre-tested for Study 2: studies 3 and 4 use behavioral measures to supplement intention measures.

The studies conducted in this dissertation provide mixed results regarding the effect of self-brand connection on consumer behavior during the goal pursuit. Effects such as the influence of self-brand connection on perceived progress and subsequent choices were consistent 
during three studies except the last one. Other measures that were included for expletory reasons such as perceived goal difficulties and goal commitment suggest that the influence of self-brand connection is wide and illuminate the importance of this construct for future researchers. While results were inconsistent, it provided initial evidence that the relationship of self-brand connection with perceived progress, subsequent choices, and perceived goal difficulty deserve further studies and investigation.

In addition, studies conducted in this dissertation could help managers who are selling these devices by showing the importance of self-brand connection and self-serving attribution biases in building strong relationships between consumers and brands to help consumers achieve their goals and provide the right feedback at the right time to enhance their chances of success. Also, the results of the studies conducted in this dissertation could suggest two things that should be taken into consideration by managers who are selling these devices: (1) Instead of just focusing on improving the technical capabilities of these devices, managers should also work on improving the relationships consumers have with the brand itself, (2) and frame the feedback messages in a manner that would motivate consumers to make more goal-consistent choices regardless of the progress level they are receiving. Accordingly, based on the relationship consumers have with the brand, companies could frame their messages and choose the right tone in

\section{Future Research}

In the studies conducted in this dissertation, progress leads to both goal-consistent and goalinconsistent choices. While some argue that goal-inconsistent choices could be an adaptive behavior during goal failure, it is essential to distinguish between the situations where progress could lead to goal-consistent choices and situations where progress could lead to goal-consistent 
choices. One possible factor is the type of feelings and mindset consumers are experiencing during the time they receive feedback about their progress. For example, consumers select compensatory brands when their self-acceptance is low but choose adaptive brands when their self-acceptation is high (Kim \& Gal 2014). In the same manner, consumers with high selfacceptance are more likely to behave differently compared to those with low self-acceptance when they receive self-deficit information (i.e., goal failure or lack or progress). Also, selfcompletion theory (Wicklund and Gollwitzer 1981) explain how individuals who are pursuing self-defining goals could engage in alternate goal-directed behaviors to achieve higher-order goals, and when they encounter self-deficit information they tend to engage in compensatory consumption to overcome the feeling of "self-definitional incompleteness" In the same manner, consumers who encounter progress information could engage in goal-consistent, or inconsistent, choices based on their feelings during the goal pursuit and how they perceive their self-concept in relation to the goal they are pursuing. 


\section{References}

Aaker, D. A. (1998). Marcas: brand equity: gerenciando o valor da marca. Gulf Professional Publishing.

Ajzen, I. (1985). From intentions to actions: A theory of planned behavior. In Action control (pp. 11-39). Springer, Berlin, Heidelberg.

Ajzen, I. (1988). Attitudes. Personality and Behavior, 134.

Amir, O., \& Ariely, D. (2008). Resting on laurels: the effects of discrete progress markers as subgoals on task performance and preferences. Journal of Experimental Psychology: Learning, Memory, and Cognition, 34(5), 1158.

Ariely, D., \& Levav, J. (2000). Sequential choice in group settings: Taking the road less traveled and less enjoyed. Journal of consumer Research, 27(3), 279-290.

Austin, J. T., \& Vancouver, J. B. (1996). Goal constructs in psychology: Structure, process, and content. Psychological bulletin, 120(3), 338.

Bagozzi, R. P., \& Dholakia, U. (1999). Goal setting and goal striving in consumer behavior. Journal of marketing, 63(4_suppl1), 19-32.

Bagozzi, R. P., \& Warshaw, P. R. (1990). Trying to consume. Journal of consumer research, $17(2), 127-140$.

Bagozzi, R. P., Gopinath, M., \& Nyer, P. U. (1999). The role of emotions in marketing. Journal of the academy of marketing science, 27(2), 184-206. 
Bandura, A. (1989). Human agency in social cognitive theory. American psychologist, 44(9), 1175.

Bandura, A. (1991). Social cognitive theory of self-regulation. Organizational behavior and human decision processes, 50(2), 248-287.

Bandura, A. (1997). The anatomy of stages of change. American journal of health promotion: AJHP, 12(1), 8.

Bargh, J. A., Gollwitzer, P. M., Lee-Chai, A., Barndollar, K., \& Trötschel, R. (2001). The automated will: nonconscious activation and pursuit of behavioral goals. Journal of personality and social psychology, 81(6), 1014.

Baumeister, R. F., Vohs, K. D., \& Tice, D. M. (2007). The strength model of self-control. Current directions in psychological science, 16(6), 351-355.

Blackston, M. (1993). Beyond brand personality: building brand relationships. Brand equity and advertising: Advertising's role in building strong brands, 113-124.

Botvinick, M. M., Braver, T. S., Barch, D. M., Carter, C. S., \& Cohen, J. D. (2001). Conflict monitoring and cognitive control. Psychological review, 108(3), 624.

Brandstätter, V. (2003). Persistenz und Zielablösung [Persistence and goal disengagement]. Göttingen, Germany: Hogrefe.

Brandtstädter, J., Rothermund, K., \& Schmitz, U. (1997). Coping resources in later life. European Review of Applied Psychology/Revue Européenne de Psychologie Appliquée. 
Brehm, J. W., \& Self, E. A. (1989). The intensity of motivation. Annual review of psychology, 40(1), 109-131.

Brick, D. J., \& Fitzsimons, G. J. (2017). Oppositional brand choice: Using brands to respond to relationship frustration. Journal of Consumer Psychology, 27(2), 257-263.

Carver, C. S., \& Scheier, M. F. (1982). Control theory: A useful conceptual framework for personality-social, clinical, and health psychology. Psychological bulletin, 92(1), 111.

Carver, C. S., \& Scheier, M. F. (1998). On the self-regulation of behavior. New York, NY: Cambridge.

Carver, C. S., \& Scheier, M. F. (1999). Themes and issues in the self-regulation of behavior. Advances in social cognition, 12(1), 1.

Carver, C. S. (2005). Impulse and constraint: Perspectives from personality psychology, convergence with theory in other areas, and potential for integration. Personality and social psychology review, 9(4), 312-333.

Chartrand, T. L., \& Bargh, J. A. (1996). Automatic activation of impression formation and memorization goals: Nonconscious goal priming reproduces effects of explicit task instructions. Journal of personality and Social Psychology, 71(3), 464.

Chen, R. P., Wan, E. W., \& Levy, E. (2017). The effect of social exclusion on consumer preference for anthropomorphized brands. Journal of Consumer Psychology, 27(1), 23 34. 
Cheng, S. Y., White, T. B., \& Chaplin, L. N. (2012). The effects of self-brand connections on responses to brand failure: A new look at the consumer-brand relationship. Journal of Consumer Psychology, 22(2), 280-288.

Cryder, Cynthia E., George Loewenstein, and Howard Seltman. "Goal gradient in helping behavior." Journal of Experimental Social Psychology 49.6 (2013): 1078-1083

Dalton, A. N., \& Spiller, S. A. (2012). Too much of a good thing: The benefits of implementation intentions depend on the number of goals. Journal of Consumer Research, 39(3), 600-614.

Dhar, R., \& Simonson, I. (1999). Making complementary choices in consumption episodes: Highlighting versus balancing. Journal of Marketing Research, 36(1), 29-44.

Drolet, A. (2002). Inherent rule variability in consumer choice: Changing rules for change's sake. Journal of Consumer Research, 29(3), 293-305.

Dweck, C. S. (1999). Self-theories: Their role in motivation, personality, and development. Philadelphia. Taylor \& Francis.

Escalas, J. E., \& Bettman, J. R. (2003). You are what they eat: The influence of reference groups on consumers' connections to brands. Journal of consumer psychology, 13(3), 339-348.

Escalas, J. E., \& Bettman, J. R. (2005). Self-construal, reference groups, and brand meaning. Journal of consumer research, 32(3), 378-389.

Fishbach, Ayelet, and Ravi Dhar. "Goals as excuses or guides: The liberating effect of perceived goal progress on choice." Journal of Consumer Research 32.3 (2005): 370-377. 
Fishbach, A., Zhang, Y., \& Koo, M. (2009). The dynamics of self-regulation. European Review of Social Psychology, 20(1), 315-344.

Fitzsimons, G. M., \& Fishbach, A. (2010). Shifting closeness: Interpersonal effects of personal goal progress. Journal of personality and social psychology, 98(4), 535.

Fournier, S. (1998). Consumers and their brands: Developing relationship theory in consumer research. Journal of consumer research, 24(4), 343-373.

Fournier, S., \& Alvarez, C. (2012). Brands as relationship partners: Warmth, competence, and in-between. Journal of Consumer Psychology, 22(2), 177-185.

Gao, L., Wheeler, S. C., \& Shiv, B. (2009). The "shaken self": Product choices as a means of restoring self-view confidence. Journal of Consumer Research, 36(1), 29-38.

Ghassemi, M., Bernecker, K., Herrmann, M., \& Brandstätter, V. (2017). The process of disengagement from personal goals: reciprocal influences between the experience of action crisis and appraisals of goal desirability and attainability. Personality and Social Psychology Bulletin, 43(4), 524-537.

Gollwitzer, P. M., \& Brandstätter, V. (1997). Implementation intentions and effective goal pursuit. Journal of personality and social psychology, 73(1), 186.

Gollwitzer, P. M., \& Moskowitz, G. B. (1996). Goal effects on action and cognition (pp. 361399).

Gollwitzer, P. M., \& Bayer, U. (1999). Deliberative versus implemental mindsets in the control of action. Dual-process theories in social psychology, 403-422. 
Harkin, Benjamin, Thomas L. Webb, Betty PI Chang, Andrew Prestwich, Mark Conner, Ian Kellar, Yael Benn, and Paschal Sheeran. "Does monitoring goal progress promote goal attainment? A meta-analysis of the experimental evidence." Psychological bulletin 142, no. 2 (2016): 198

Haws, K. L., \& Redden, J. P. (2013). In control of variety. High self-control reduces the effect of variety on food consumption. Appetite, 69, 196-203.

Heatherton, T. F., \& Baumeister, R. F. (1991). Binge eating as escape from self-awareness. Psychological bulletin, 110(1), 86.

Heckhausen, H. (1977). Achievement motivation and its constructs: A cognitive model. Motivation and emotion, 1(4), 283-329.

Heckhausen, H., \& Gollwitzer, P. M. (1987). Thought contents and cognitive functioning in motivational versus volitional states of mind. Motivation and emotion, 11(2), 101-120.

Higgins, E. T. (1987). Self-discrepancy: a theory relating self and affect. Psychological review, 94(3), 319.

Higgins, E. T. (1997). Beyond pleasure and pain. American psychologist, 52(12), 1280.

Hoch, S. J., \& Loewenstein, G. F. (1991). Time-inconsistent preferences and consumer selfcontrol. Journal of consumer research, 17(4), 492-507.

Hofmann, W., Friese, M., \& Strack, F. (2009). Impulse and self-control from a dual-systems perspective. Perspectives on psychological science, 4(2), 162-176. 
Hollenbeck, J. R., \& Klein, H. J. (1987). Goal commitment and the goal-setting process:

Problems, prospects, and proposals for future research. Journal of Applied Psychology, $72(2), 212-220$.

Karniol, R., \& Ross, M. (1996). The motivational impact of temporal focus: Thinking about the future and the past. Annual review of psychology, 47(1), 593-620.

Karoly, P. (1993). Mechanisms of self-regulation: A systems view. Annual review of psychology, 44(1), 23-52.

Kim, S., \& Gal, D. (2014). From compensatory consumption to adaptive consumption: The role of self-acceptance in resolving self-deficits. Journal of Consumer Research, 41(2), 526542.

Kivetz, R., \& Simonson, I. (2002). Earning the right to indulge: Effort as a determinant of customer preferences toward frequency program rewards. Journal of Marketing Research, $39(2), 155-170$.

Kivetz, Ran, Oleg Urminsky, and Yuhuang Zheng. "The goal-gradient hypothesis resurrected: Purchase acceleration, illusionary goal progress, and customer retention." Journal of Marketing Research 43.1 (2006): 39-58

Koo, Minjung, and Ayelet Fishbach. "The small-area hypothesis: Effects of progress monitoring on goal adherence." Journal of Consumer Research 39, no. 3 (2012): 493-509 
Kruglanski, A. W. (1996). Goals as knowledge structures. In P. M. Gollwitzer \& J. A. Bargh

(Eds.), The psychology of action: Linking cognition and motivation to behavior (p. 599618). Guilford Press.

Kuhl, J. (1982). The expectancy-value approach within the theory of social motivation: Elaborations, extensions, critique. Expectations and actions: Expectancy-value models in psychology, 42(2), 125-160.

Kuhl, J., \& Beckmann, J. (1994). Alienation: Ignoring one’s preferences. Volition and personality: Action versus state orientation, 375-390.

Latham, Gary P., and Edwin A. Locke. "Self-regulation through goal setting." Organizational behavior and human decision processes 50, no. 2 (1991): 212-247.

Latham, G. P., \& Locke, E. A. (1991). Self-regulation through goal setting. Organizational behavior and human decision processes, 50(2), 212-247.

Locke, E. A., \& Latham, G. P. (1990). A theory of goal setting \& task performance. PrenticeHall, Inc.

Locke E. A., Shaw, K. N., Snarl, L. M., \& Latham, G. P. (1981). Goal setting and task performance: 1969-1980. Psychological Bulletin, 90, 125-152.

Long, C., Yoon, S., \& Friedman, M. (2014). Of Ostracism, Loneliness and Consumer-Brand Relationships. In Society for Personality and Social Psychology. 
MacInnis, D. J., \& Folkes, V. S. (2017). Humanizing brands: When brands seem to be like me, part of me, and in a relationship with me. Journal of Consumer Psychology, 27(3), 355374.

Markus, H., \& Wurf, E. (1987). The dynamic self-concept: A social psychological perspective. Annual review of psychology, 38(1), 299-337.

Miller, G. A., Galanter, E., \& Pribram, K. H. (1960). Plans and the structure of behavior.

Muniz, A. M., \& O'guinn, T. C. (2001). Brand community. Journal of consumer research, 27(4), 412-432.

Oettingen, G. (1996). Positive fantasy and motivation. The psychology of action: Linking cognition and motivation to behavior, 236 .

Oettingen, G., \& Gollwitzer, P. M. (2001). Goal setting and goal striving.

Peloza, J., White, K., \& Shang, J. (2013). Good and guilt-free: The role of self-accountability in influencing preferences for products with ethical attributes. Journal of Marketing, 77(1), 104-119.

Pervin, L. A. (1989). 12 Goals Concepts: Themes, Issues, and Questions. Goal concepts in personality and social psychology, 473.

Powers, W. T. (1973). Feedback: Beyond Behaviorism: Stimulus-response laws are wholly predictable within a control-system model of behavioral organization. Science, 179(4071), 351-356. 
Ratner, R. K., Kahn, B. E., \& Kahneman, D. (1999). Choosing less-preferred experiences for the sake of variety. Journal of consumer research, 26(1), 1-15.

Read, D., \& Loewenstein, G. (1995). Diversification bias: Explaining the discrepancy in variety seeking between combined and separated choices. Journal of Experimental Psychology: Applied, 1(1), 34 .

Righetti, F., Kumashiro, M., \& Campbell, S. B. (2014). Goal difficulty and openness to interpersonal goal support. Personality and Social Psychology Bulletin, 40(9), 1107 1118.

Rucker, D. D., \& Galinsky, A. D. (2008). Desire to acquire: Powerlessness and compensatory consumption. Journal of Consumer Research, 35(2), 257-267.

Ryan, R. M., \& Deci, E. L. (2000). Intrinsic and extrinsic motivations: Classic definitions and new directions. Contemporary educational psychology, 25(1), 54-67.

Ruvolo, A. P., and H. Markus. "Possible selves and motivation." Social Cognition (1986).

Schlenker, B. R. (1985). Identity and self-identification. The self and social life, 65, 99.

Senko, C., \& Harackiewicz, J. M. (2005). Regulation of achievement goals: the role of competence feedback. Journal of Educational Psychology, 97(3), 320.

Sirgy, M. J. (1982). Self-concept in consumer behavior: A critical review. Journal of consumer research, 9(3), 287-300.

Skinner, B. F. (1953). Science and human behavior. New York: Mkrillin 
Taylor, S. E., Pham, L. B., Rivkin, I. D., \& Armor, D. A. (1998). Harnessing the imagination: Mental simulation, self-regulation, and coping. American psychologist, 53(4), 429.

Trope, Y., \& Fishbach, A. (2000). Counteractive self-control in overcoming temptation. Journal of personality and social psychology, 79(4), 493.

Van Osselaer, S. M., \& Janiszewski, C. (2012). A goal-based model of product evaluation and choice. Journal of Consumer Research, 39(2), 260-292.

Vann, R. J., Rosa, J. A., \& McCrea, S. M. (2018). When consumers struggle: Action crisis and its effects on problematic goal pursuit. Psychology \& Marketing, 35(9), 696-709.

Vigneron, F., \& Johnson, L. W. (1999). A review and a conceptual framework of prestigeseeking consumer behavior. Academy of marketing science review, 1(1), 1-15.

Wright, R. A., \& Brehm, J. W. (1989). Energization and goal attractiveness.

Wright, P. M., \& Kacmar, K. M. (1994). Goal specificity as a determinant of goal commitment and goal change. Organizational Behavior and Human Decision Processes, 59(2), 242260.

Wrosch, C., Scheier, M. F., Miller, G. E., Schulz, R., \& Carver, C. S. (2003). Adaptive selfregulation of unattainable goals: Goal disengagement, goal reengagement, and subjective well-being. Personality and social psychology bulletin, 29(12), 1494-1508.

Zhang, Y., \& Huang, S. C. (2010). How endowed versus earned progress affects consumer goal commitment and motivation. Journal of Consumer Research, 37(4), 641-654. 


\section{APPENDIX A \\ STUDY 4 ANAGRAM TASK ON-SCREEN INSTRUCTIONS}

The first screen read:

The QT Ranking problem solving task is next. You will be unscrambling sets of letters to form (correctly spelled) words. This is known as an ANAGRAM puzzle and involves problem solving skills.

Your goal is to solve at least 5 anagrams. This is the number the average college student is able to solve in two minutes. You will also have a 2-minute timer.

If you are successful by correctly solving at least 5 anagrams within 2-minutes, you will earn 2 Scholar dollars to use to purchase snacks from the new Scholaris Cafe downstairs in the CBC Lobby.

Then, the next screen read:

\section{DIRECTIONS:}

For this competitive task, you will be solving anagrams. You will see 10 groups of scrambled letters. You may use 2 or more letters to make any real word in the English language. No foreign words. Please create 1 word per letter group.

For example, the letters "a m d e n" can be used to create the words mad, me, dean, damn, den, dam, dame, or dane. 
The subsequent screen then showed them these instructions:

Whichever word comes to mind FIRST when you see the group of letters is the word you should write in the space provided. The number of anagrams solved in the time provided will be your score. All words earn 1 point, regardless of length or complexity. Your goal is to earn $\mathbf{5}$ points.

And lastly, the next screen showed them these instructions:

Remember, you may use 2 or more letters to make any real word in the English language. No foreign words.

Only create 1 word per letter group.

You can skip around and leave some blank if you choose.

Whichever word comes to mind FIRST when you see the group of letters is the word you should write in the space provided.

Create as many words as you can in 2 minutes. 


\section{APPENDIX B}

\section{STUDY 4 ANAGRAM TASKS}

\section{High goal progress task}

\section{QT University Ranking: Problem-Solving Assessment}

DIRECTIONS: Below there are 10 groups of scrambled letters. You may use $\mathbf{2}$ or more letters to make any real word in the English language. No foreign words. Please create 1 word per letter group.

For example, the letters "a m d e n" can be used to create the words mad, me, dean, damn, den, dam, dame, or dane.

Whichever word comes to mind FIRST when you see the group of letters is the word you should write in the space provided. The number of anagrams solved in the time provided will be your score. All words earn 1 point, regardless of length or complexity. Your goal is to earn 5 points.

You can skip around and leave some blank if you choose.

1. ouht

2. tcs a

3. If et

4. $a n b d$

5. $\mathrm{krba}$

6. i o $\mathrm{mt}$

7. p s to 
Self-Brand Connection Effects on Consumers Goal Pursuit Behavior

8. $\operatorname{tcra}$

9. $\mathrm{m} \mathrm{n} \mathrm{y} \mathrm{a}$

10. $\mathrm{CW}$ o $\mathrm{h}$

\section{Low goal progress task}

\section{QT University Ranking: Problem-Solving Assessment}

DIRECTIONS: Below there are 10 groups of scrambled letters. You may use $\mathbf{2}$ or more letters to make any real word in the English language. No foreign words. Please create 1 word per letter group.

For example, the letters "a m d e n" can be used to create the words mad, me, dean, damn, den, dam, dame, or dane.

Whichever word comes to mind FIRST when you see the group of letters is the word you should write in the space provided. The number of anagrams solved in the time provided will be your score. All words earn 1 point, regardless of length or complexity. Your goal is to earn 5 points.

You can skip around and leave some blank if you choose.

1. $\mathrm{t} z \mathrm{er}$

2. $r c s o$

3. If et

4. $\mathrm{n} \mathrm{b} \mathrm{do}$

5. $\mathrm{krsa}$ 
Self-Brand Connection Effects on Consumers Goal Pursuit Behavior

6. I $u m t$

7. psto

8. $\mathrm{tcre}$

9. $\mathrm{mnya}$

10. cwe h 
VITA

\section{AHMED ALRADADI}

2014 - Present

2011-Present

2012

$2011-2012$

2011-2012

2008-2009

2004-2008

2006-2007
Florida International University - Doctoral Program

Social Media Marketing Consultant, Middle East - Helping small businesses to target the right audience in different social media platforms, and work with entrepreneurs to deliver the appropriate content in the right platform.

Marketing Research, Lycée Franco American International School, Plantation, Fl - Conducted a marketing research project of a private school in South Florida. Project included statistic analysis of the data collected as well as the development of a set of recommendation to the senior management team.

Barry University - MBA

Marketing Strategy, O Cinema, Miami, Fl - Conducted a primary marketing research, analyze the data collected and develop a marketing strategy for the company.

Teaching Assistance, King Abdulaziz University, Jeddah, Saudi Delivered lectures about marketing and e-commerce. Participated in the accreditation process of the college (American Council on Occupational Education)

King Abdulaziz University - Bachelor Of Science In Business

Salesman, Marketing Pulse Trade \& Marketing Enterprise; Jeddah, Saudi - Participated in designing the marketing campaign of 7carwash arabia in Jeddah 